\title{
Comparison of Fuzzy AHP and Fuzzy TOPSIS for Road Pavement Maintenance Prioritization: Methodological Exposition and Case Study
}

\author{
Yashon O. Ouma, J. Opudo, and S. Nyambenya \\ Department of Civil and Structural Engineering, Moi University, P.O. Box 3900, Eldoret 30100, Kenya \\ Correspondence should be addressed to Yashon O. Ouma; yashon_o@hotmail.com
}

Received 30 April 2015; Revised 15 June 2015; Accepted 16 June 2015

Academic Editor: Samer Madanat

Copyright (C) 2015 Yashon O. Ouma et al. This is an open access article distributed under the Creative Commons Attribution License, which permits unrestricted use, distribution, and reproduction in any medium, provided the original work is properly cited.

\begin{abstract}
For road pavement maintenance and repairs prioritization, a multiattribute approach that compares fuzzy Analytical Hierarchy Process (AHP) and fuzzy Technique for Order Preference by Ideal Situation (TOPSIS) is evaluated. The pavement distress data was collected through empirical condition surveys and rating by pavement experts. In comparison to the crisp AHP, the fuzzy AHP and fuzzy TOPSIS pairwise comparison techniques are considered to be more suitable for the subjective analysis of the pavement conditions for automated maintenance prioritization. From the case study results, four pavement maintenance objectives were determined as road safety, pavement surface preservation, road operational status and standards, and road aesthetics, with corresponding depreciating significance weights of $W=[0.37,0.31,0.22,0.10]^{T}$. The top three maintenance functions were identified as Thin Hot Mix Asphalt (HMA) overlays, resurfacing and slurry seals, which were a result of pavement cracking, potholes, raveling, and patching, while the bottom three were cape seal, micro surfacing, and fog seal. The two methods gave nearly the same prioritization ranking. In general, the fuzzy AHP approach tended to overestimate the maintenance prioritization ranking as compared to the fuzzy TOPSIS.
\end{abstract}

\section{Introduction}

Road pavement condition survey and assessment are an important component in the decision making procedure in pavement management systems (PMS). The two main reasons for the assessment of pavement condition are to recognize and prioritize maintenance requirements in specific road sections and to identify the pavement network conditions and, if any, the rehabilitation requirements [1]. In urban road maintenance and rehabilitation (M\&R) projects, the evaluation of road pavement conditions is the initial phase that guarantees suitable and sustainable maintenance programs [2].

For pavement M\&R projects, specific pavement maintenance management systems (PMMS) should be proposed, as suitable systems for the improvement of the efficiency of decision making. Furthermore, such systems should be able to provide feedbacks on the impacts of the decisions in terms of short and long term maintenance strategies and with respect to cost-benefit analysis [3]. A typical structure that integrates PMS, PMMS, and M\&R is depicted in Figure 1.

From Figure 1, it is seen that a PMS is supposed to be a coordinated and systematic process for carrying out all activities related to providing and maintaining pavements. On the other hand a PMMS should be able to predict the pavement condition and the cost associated with its M\&R over a given time frame and also to aid in the planning and programming of the associated M\&R works. In implementing PMMS, multicriteria priority ranking and analysis can be used to rank and select pavement sections due for maintenance in the order of urgency. PMMS is considered to be a timely, cost-beneficial, and preventive $M \& R$ approach in the maintenance as compared to the traditional reactive $M \& R$ approach.

Pavement Maintenance Prioritization Using Multicriteria Decision Approach. The main multicriteria decision making approach is the Analytic Hierarchy Process (AHP) which was 


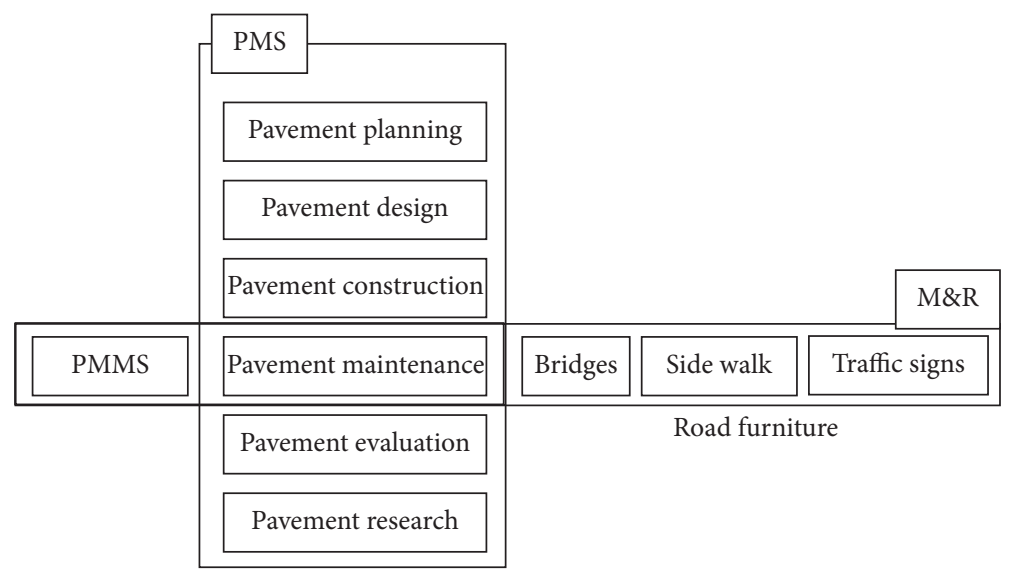

FIGURE 1: Schematic structure of a typical pavement management system (PMS) and pavement maintenance and management system (PMMS).

introduced by Saaty in the 1970s [4, 5]. Saaty developed AHP to primarily meet the complexities and challenges of decision situations that are brought out by multiple and conflicting criteria as a multicriteria decision making (MCDM) tool. AHP aids decision makers in determining the best criteria out of multiple sets of criteria, based on crisp or exact numerical values.

On road pavement maintenance priority ranking and analysis, AHP has been widely used (e.g., [6, 7]). However, due to the fact that in most practical situations the human preference is marred by uncertainty, decision makers would find it difficult to explicitly assign exact numerical values to the comparison judgments [8]. Therefore the decision maker would theoretically find it very difficult to express the strength of his preferences and confidence in terms of the AHP in pairwise comparison judgments. As such AHP has been argued to be ineffective when employed to ambiguous or vaguely represented real-life problems that consist of uncertainty and subjectivity [9].

In decision making processes, uncertainty, imprecision, and subjectivity can be handled by means of probability theory and or fuzzy set theory (FST) [10]. While probability focuses on the stochasticity of the decision making process, FST tends to formalize the subjective and imprecise nature of human behavior by representing and quantifying vague information through a membership grade function [10]. As such, probabilistic theory is not adequately suited for subjectivity and imprecision in the human decision making process [11-14].

The advantage of fuzzy based pairwise comparison is that it allows decision makers to be more flexible in their judgments. This is attained through the different degrees of fuzzification. Furthermore if there is need for consideration of the attitude toward risk, FTS has the possibility of overlapping preferences of criteria in case the expert is not confident about the degree of importance within a set of decisions and there is the provision for interval decision as expressed by a fuzzy membership function [15]. FST can also be considered useful in decision problems where the degrees of uncertainty are expected to increase or change in time, for example, in pavement failure and deterioration, where different conditions are expected to change with time, but there is no predictive information on the future state.

In order to accommodate uncertainty in experts' heuristic and experiential judgments, Shah et al. [3] used the ranking of road maintenance factors based on subjective rating. And to take care of subjectivity in judgment, fuzzy pairwise comparison deduction technique can be integrated with AHP $[3,16,17]$. Used independently, fuzzy AHP results are directly ranked according to the normalized weights. However, in real life decision, decision makers' degrees of confidence and attitudes to risks should be taken into consideration.

Fuzzy Technique for Order Preference by Ideal Situation (TOPSIS) technique operates on the basis that the most preferred decision alternative should not only have the shortest distance from a positive ideal solution (PIS), but also have the farthest distance from the negative ideal solution (NIS), hence its capability and efficiency in handling uncertainty $[18,19]$. However the use of Euclidean Distance as determined from PIS and NIS in TOPSIS does not consider the correlation of attributes and that makes it difficult to derive the weights of the decision attributes while keeping the judgment consistency [20]. Thus the integration fuzzy TOPSIS with AHP is considered in this study, in addition to taking into account the degree of confidence in decision making.

In this study, fuzzy approach, allowing experts to use linguistic variables, is considered for prioritization by applying and comparing the results from fuzzy AHP and fuzzy TOPSIS. The classical AHP is utilized to determine the weight vector of road maintenance factors with respect to the set objectives. In principle, therefore, the two approaches differ primarily in the way the fuzzy ratings are aggregated and normalized but do impact on the data collection procedure.

First, a methodological overview and approach for fuzzy AHP and fuzzy TOPSIS for the formulation and automation of cost-effective PMMS for consistent and reliable prioritization of $M \& R$ of road pavements in urban areas are presented. In the implementation, a case study in Eldoret Town in Kenya is used. For thematic display of the road network, a graphical user interface was designed in GIS and 


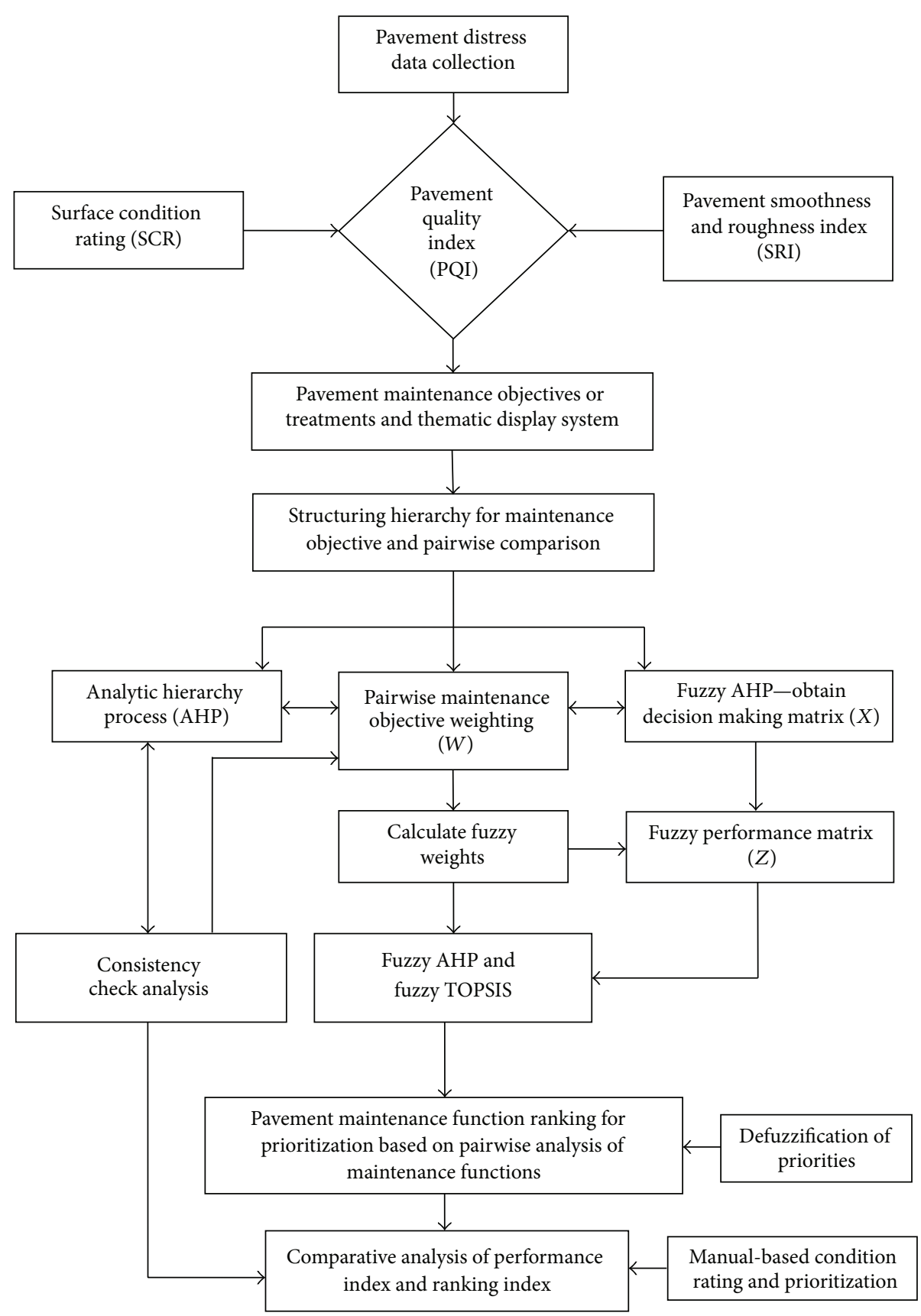

FIGURE 2: Schematic framework for road pavement prioritization using fuzzy AHP and fuzzy TOPSIS.

SQL database management systems. In summary, Figure 2 presents the schematic framework for the methodological approach in this study.

The rest of the paper is organized as follows. Section 2 is on the case study pavement distress data collection, cataloging, and display. Section 3 presents the methodological overview and approach based on fuzzy AHP and fuzzy TOPSIS. Section 4 presents the results of the case study, and Section 5 presents the analysis and discussions of the results. The study conclusions and recommendations are presented in Section 6.

\section{Case Study Pavement Distress Catalogue and Display}

There are two main approaches for the collection of pavement distress data: manual (visual inspection) distress data collection and automated distress data collection [21]. For cost-effective and simplified pavement condition surveys, this study adopted empirically manual-based inspection approach to identify the pavement failures or distresses. GPS was used to obtain the chainages of the observed pavement failures and to locate the associated pavement distresses. 


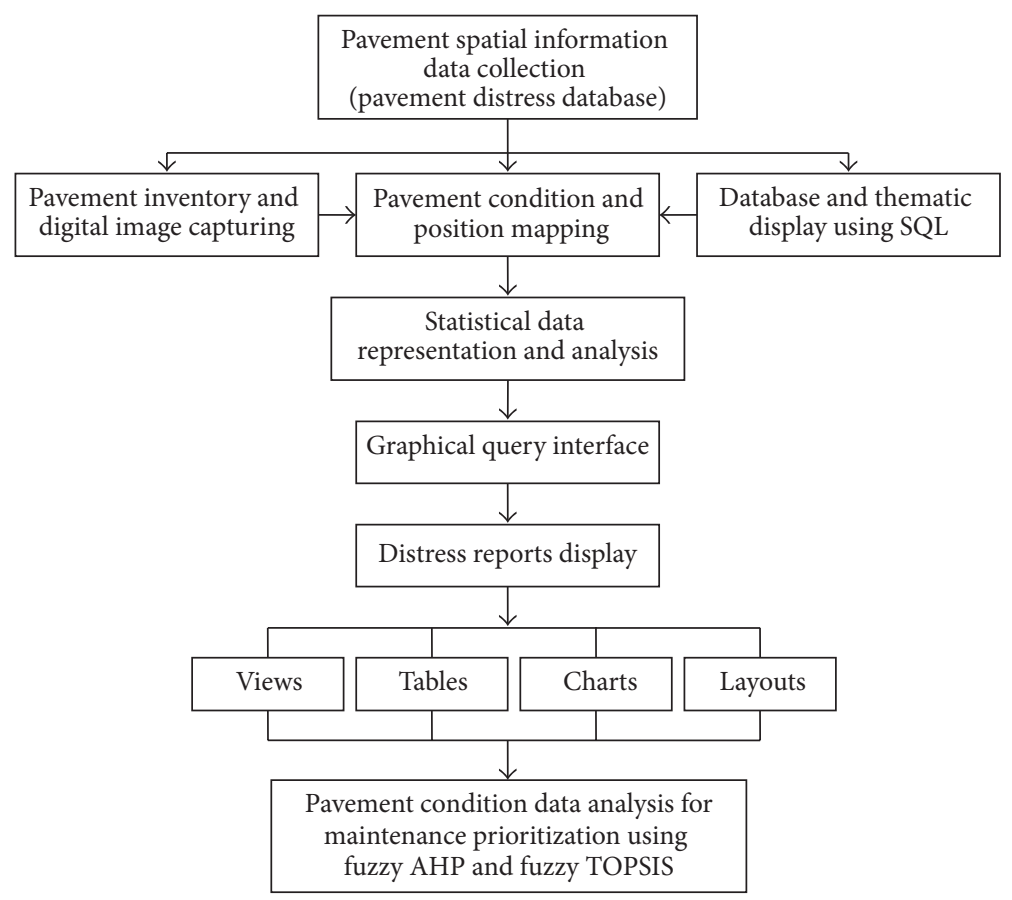

FIGURE 3: Proposed framework for pavement inventory and condition survey thematic display system.

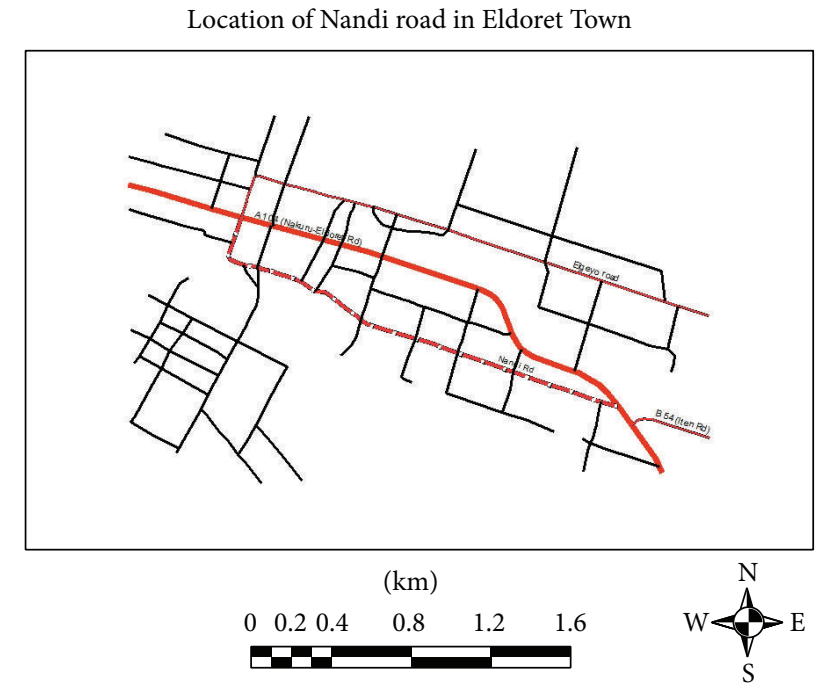

— Nakuru-Eldoret road
- Nandi road

FIGURE 4: Study road and the adjoining roads digitized and georeferenced from Google Maps image and GPS field observations.

A summary of the structure for the pavement distress catalogue and display system is presented in Figure 3. The result of this stage of mapping is presented in Figure 4 for the case study of Nandi road in Eldoret Town (Kenya).

2.1. Pavement Distress Inventorying and Failure Index. Since the collection of detailed pavement condition data is very costly and time-consuming, innovative approaches for rapid data collection are in increasing demand among highway agencies with limited PMS budgets [22]. For the case study, visual based empirical inspection and rating (ECR), for distresses data collection, was adopted for the $3 \mathrm{~km}$ Nandi road, with observations made at $300 \mathrm{~m}$ segments. For each inspected segment of the road, a digital image of the observed distresses was also captured for thematic display.

In order to determine the degree of distress failure two approaches are used. One is a surface condition rating (SCR) to define the failure criteria for cracking and pothole based distresses. According to the proposed SCR, a rating scale of 0-3 was adopted, with a new road surface (no pothole, no cracking) having an SCR of 3 . As the amount and severity of the defect increase, the SCR also drops. That implies that low cracking has an SCR of 3, while medium to severe cracking ranges from 2 to 0 . In terms of the defect extent, defined by the depth, area, and/or length, an SCR of 3 implies negligible defects, while SCR index values of 2-0 imply wide or long defects that require repairs.

The second component of pavement failure is the pavement surface ride quality. This was characterized by patching and raveling distresses indicators and expressed in terms of the degree of smoothness or roughness index (SRI). The SRI is also ranked between 3 and 0 , such that a new road pavement would have an SRI of 3. SRI indices of between 2 and 1 imply that the road has deteriorated to the extent where motorists feel that it is uncomfortable driving on and therefore needs rehabilitation. An SRI of 0 then means that there is complete surface failure requiring major rehabilitation, as is characterized by continuous cracking, potholes, patching, and raveling distresses. The pavement distresses that make up the general pavement condition are determined by the expert judges 
comprising of pavement engineers and road inspectors from the road management department.

From the experts' judgments and analyses, it was deduced that the overall road pavement quality index (PQI) indicator is defined by the geometric mean of SCR and SRI as expressed in (1). In (1), PQI values range from 3 to 0 with a PQI value of between 2 and 0 implying that the pavement is subject to maintenance and/or rehabilitation:

$$
\mathrm{PQI}=\sqrt{\mathrm{SCR} * \mathrm{SRI}} .
$$

In the implementation, it is recommended that PQI indices should not be rounded off; that is, a PQI of $\sqrt{1 * 3}=\sqrt{3}=$ 1.732 is not equivalent to 2 . This precaution is taken in order to avoid minor repair maintenances at any given time in the pavement life-span for economic reasons, at the expense of more immediate and larger M\&R cases. From the PQI, the road pavement maintenance objectives and functions can then be derived.

A summary of the observed distress results for the $3 \mathrm{~km}$ road is presented in Table 1 . The results in Table 1 show that the distresses were mainly characterized by cracking, potholes, patching, and raveling. The results in Table 1 will be subjected to pairwise comparison and prioritization by the pavement management experts in order to determine the priority areas for M\&R activities. Figure 5 characteristically shows some of the functional and structural failures that are observed on the case study road, as summarized in Table 1.

\section{Methodology}

3.1. AHP for Decision Prioritization. AHP is often used to guide decision makers coping with multicriteria decisions involving multiattribute situations [5, 23-25]. Decision judgments as articulated by pairwise comparisons are the fundamental inputs for facilitating the AHP procedure. Every pairwise comparison results in a numerical value $a_{i j}$ representing the ratio between the weights of the two decision criteria, $i$ and $j$. The Saaty preference scale is used to assign numerical values to different levels of preferences. As a standard, the Saaty scale used for AHP ranges from 1 to 9 and reflects the importance of one factor over another as represented in Table 2.

Supposing that $C=\left\{C_{j} \mid j=1,2, \ldots, n\right\}$ is the set of criteria, then the evaluation matrix can be obtained, in which every element $a_{i j}(i, j=1,2, \ldots, n)$ represents the relative weights of the criteria illustrated:

$$
A=\left[\begin{array}{cccc}
a_{11} & a_{12} & \cdots & a_{1 n} \\
a_{21} & a_{22} & \cdots & a_{2 n} \\
\vdots & \vdots & \vdots & \vdots \\
a_{n 1} & a_{n 2} & \cdots & a_{n n}
\end{array}\right]
$$

In (2), $n$ is the number of criteria in a decision process, such that $A$ is the judgment which contains the pairwise comparison value $a_{i j}$ for all $i, j \in\{1,2, \ldots, n\}$.

For multiple decision makers or experts as is often the case, if $h$ is the number of decision makers and $a_{i j}^{k}$ is the
TABLE 1: Road condition survey data showing pavement segment chainage and the observed distresses, as derived from the PQI

\begin{tabular}{|c|c|}
\hline Segment or chainage (m) & Observed distresses \\
\hline $0-300$ & $\begin{array}{l}\text { (i) Potholes } \\
\text { (ii) Longitudinal cracks } \\
\text { (iii) Transverse cracks } \\
\text { (iv) Alligator cracks }\end{array}$ \\
\hline $300-600$ & $\begin{array}{l}\text { (i) Longitudinal cracks } \\
\text { (ii) Transverse cracks } \\
\text { (iii) Block cracking }\end{array}$ \\
\hline $600-900$ & $\begin{array}{l}\text { (i) Potholes } \\
\text { (ii) Longitudinal cracks } \\
\text { (iii) Transverse cracks } \\
\text { (iv) Alligator cracks } \\
\text { (v) Patching }\end{array}$ \\
\hline $900-1200$ & $\begin{array}{l}\text { (i) Potholes } \\
\text { (ii) Longitudinal cracks } \\
\text { (iii) Alligator cracks }\end{array}$ \\
\hline $1200-1500$ & $\begin{array}{l}\text { (i) Potholes } \\
\text { (ii) Longitudinal cracks } \\
\text { (iii) Edge cracking } \\
\text { (iv) Raveling }\end{array}$ \\
\hline $1500-1800$ & $\begin{array}{l}\text { (i) Potholes } \\
\text { (ii) Longitudinal cracks } \\
\text { (iii) Transverse cracks } \\
\text { (iv) Block cracking }\end{array}$ \\
\hline $1800-2100$ & $\begin{array}{l}\text { (i) Potholes } \\
\text { (ii) Longitudinal cracks } \\
\text { (iii) Alligator cracks }\end{array}$ \\
\hline $2100-2400$ & $\begin{array}{l}\text { (i) Potholes } \\
\text { (ii) Longitudinal cracks } \\
\text { (iii) Transverse cracks } \\
\text { (iv) Block cracking }\end{array}$ \\
\hline $2400-2700$ & $\begin{array}{l}\text { (i) Potholes } \\
\text { (ii) Longitudinal cracks } \\
\text { (iii) Alligator cracks }\end{array}$ \\
\hline $2700-3000$ & $\begin{array}{l}\text { (i) Potholes } \\
\text { (ii) Longitudinal cracks } \\
\text { (iii) Transverse cracks } \\
\text { (iv) Alligator cracks } \\
\text { (v) Block cracking } \\
\text { (vi) Raveling }\end{array}$ \\
\hline
\end{tabular}
calculations.

pairwise comparison value of criteria $i$ and $j$ given by decision maker $k$, where $k=1,2, \ldots, h$, then by using geometric mean of the $a_{i j}^{k}$ conducted by each decision maker, a new compound judgment matrix is derived, with the corresponding elements determined as follows:

$$
a_{i j}=\left(a_{i j}^{1} * a_{i j}^{2} * \cdots a_{i j}^{k} * \cdots a_{i j}^{h}\right)^{1 / h}=\left(\prod_{k=1}^{h} a_{i j}^{k}\right)^{1 / h} .
$$

The basic procedure for AHP approach as represented by the mean of normalized values method can be summarized in the following steps according to Saaty [26]: (i) normalization of each column to get a new judgment matrix $\left(A^{\prime}\right)$, (ii) summing up of each row of normalized judgment matrix 
TABle 2: The nine-point Saaty scale of relative importance [4].

\begin{tabular}{|c|c|c|}
\hline Intensity of importance & Definition & Explanation \\
\hline 1 & Equal importance & Two activities contribute equally to the objective. \\
\hline 3 & $\begin{array}{l}\text { Weak importance of one } \\
\text { over the other }\end{array}$ & $\begin{array}{l}\text { Experience and judgment slightly favour one over the } \\
\text { other. }\end{array}$ \\
\hline 5 & $\begin{array}{l}\text { Essential or strong } \\
\text { importance }\end{array}$ & $\begin{array}{l}\text { An activity is strongly favoured and its dominance is } \\
\text { demonstrated in practice. }\end{array}$ \\
\hline 7 & Demonstrated importance & $\begin{array}{l}\text { The evidence favouring over another is of highest } \\
\text { possible order of affirmation. }\end{array}$ \\
\hline 9 & Absolute importance & When compromise is needed. \\
\hline $2,4,6,8$ & Intermediate values & \\
\hline
\end{tabular}

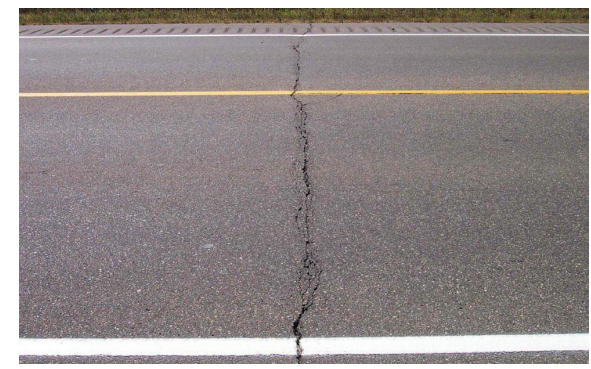

(a) Transverse cracking

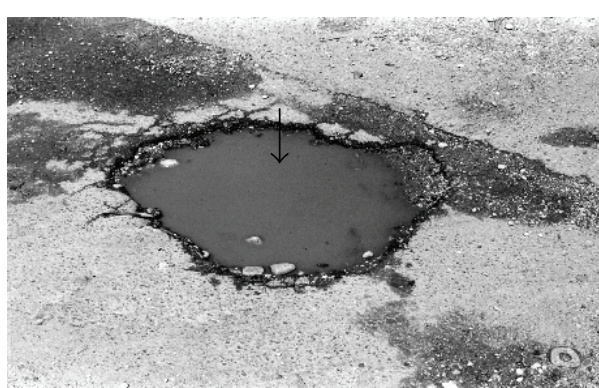

(d) Pothole

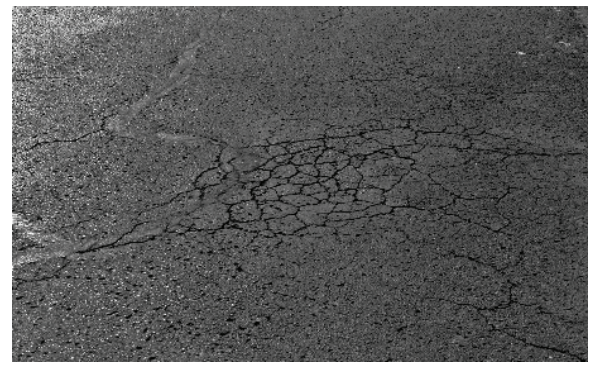

(b) Alligator (fatigue) cracking

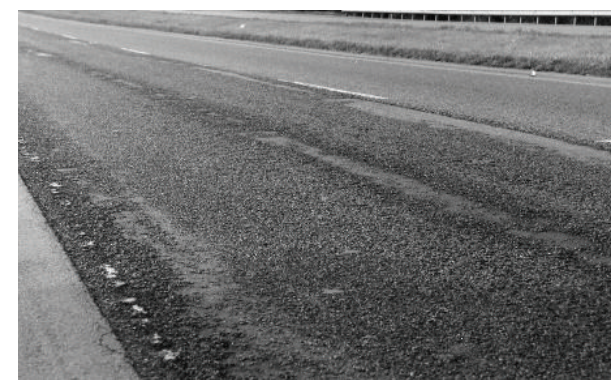

(e) Raveling-microtextural surface deformations

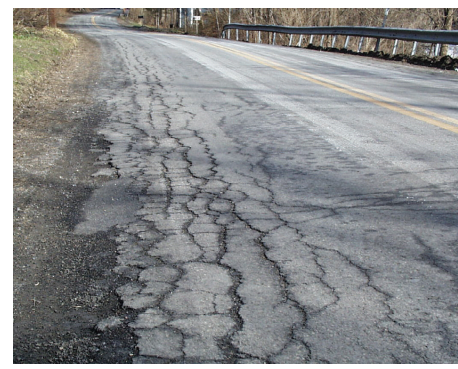

(c) Edge cracking

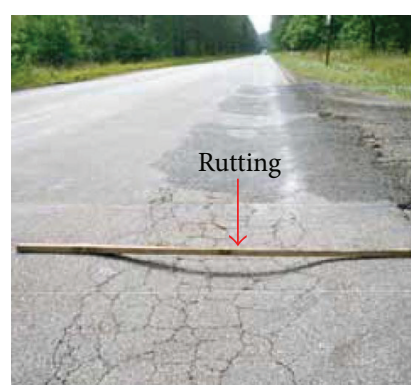

(f) Rutting and block cracking
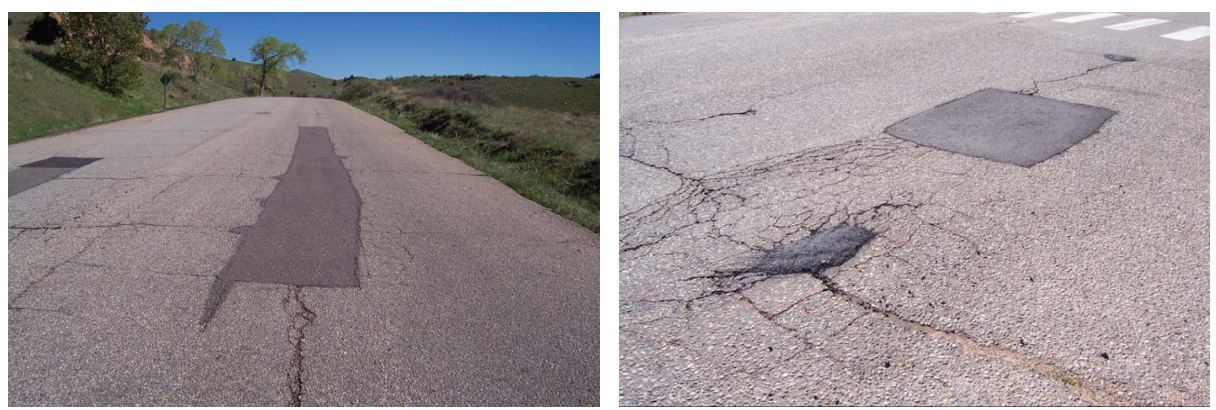

(g) Patching

FIgURE 5: Photographs of typically observed road pavement distresses.

$\left(A^{\prime}\right)$ to get weight vector $(V)$, and (iii) finally defining the final normalization weight vector $(W)$. Detailed and stepwise implementation of the AHP techniques can be found in Ouma and Tateishi [25].

According to the relative importance in Table 2, a decision maker who, for example, assigns a value of 3 to a pairwise comparison implies that the judgment slightly favours one alternative over the other. However, because of the subjective nature in linguistic decisions (e.g., very high, high, moderate, low, and very low), such an assessment cannot be accurate. Furthermore, when the decision maker's judgments are uncertain, determining such precise Saaty's static nine-point scale values may be very difficult. This means that the static crisp values may lack the ability to capture the decision 


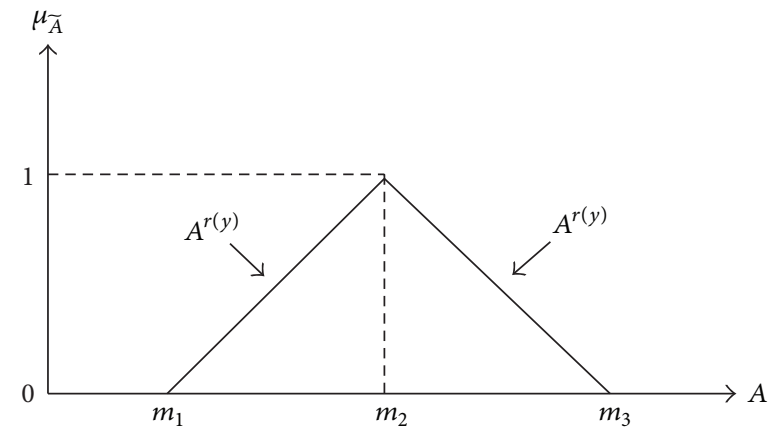

(a)

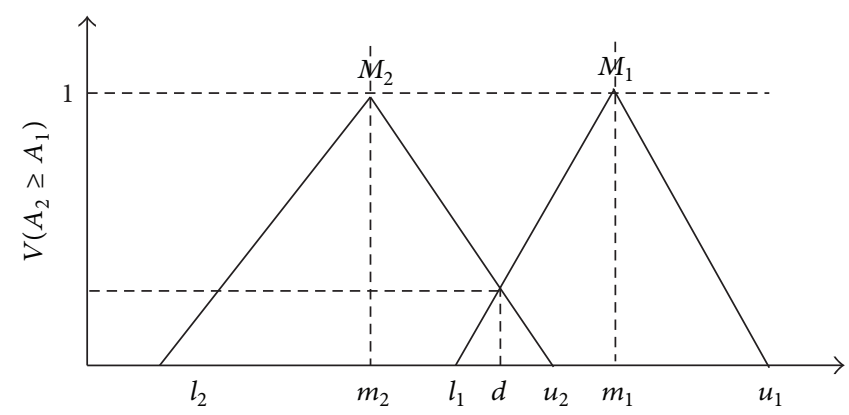

(b)

Figure 6: (a) A triangular fuzzy number, $M$, and (b) the intersection between $M_{1}$ and $M_{2}$ in extent fuzzy analysis.

makers' ambiguous and/or vague preferences. The logical way to overcome this limitation is to define the comparison ratios in terms of fuzzy numbers.

3.2. Fuzzy Sets Theory and Fuzzy AHP. In contrast to classical set theory, FST allows for the assessment of the membership of elements with respect to a set represented by $\mu=[0,1]$ [10]. The fuzzy AHP is an extension of AHP technique for multicriteria decision making in pairwise based comparisons that deals with qualitative and imprecise real-world decisions problems.

In essence fuzzy AHP is a synthetic extension of the classical AHP method when the fuzziness of the decision maker's is considered. Fuzzy AHP is comprised of the following steps in implementation: (i) structuring of the levels of hierarchy for decision making, (ii) prioritization based on fuzzy pairwise comparisons, (iii) checking for consistency of the preference judgments by the experts, (iv) synthesis of pairwise priorities, and (v) defuzzification of the determined priorities according to Chen and Hsieh [27]. Defuzzification is necessary because the fuzzy arithmetic means are not crisp values and hence cannot directly be ranked. Defuzzification thus refers to the fuzzy ranking method that is employed so as to obtain the desired nonfuzzy or crisp values [28].

A fuzzy AHP decision problem consists of a number of alternatives $\left[M_{i}(i=1,2, \ldots, m)\right]$, a set of evaluation criteria $\left[C_{j}(j=1,2, \ldots, n)\right]$, a linguistic judgment $\left(r_{i j}\right)$ representing the relative importance of each pair of criteria, and a weighting vector $\left[W=\left(w_{1}, w_{2}, \ldots, w_{n}\right)\right]$. Like the classical AHP, fuzzy AHP also has a judgment matrix. However the extent fuzzy approach uses the triangle fuzzy numbers (TFNs) instead of a constant pairwise comparison value [29]. The extent analysis based fuzzy AHP depends on the degree of possibilities of each criterion used in the decision process. TFNs for the linguistic variables from the judgments are placed according to the responses and for a particular level on the decision hierarchy, from which the pairwise comparison matrix is constructed [30,31].

According to Kaufmann and Gupta [32], a fuzzy number $\widetilde{F}$ is a triangular fuzzy number if its membership function $\mu_{\tilde{F}}(x): \Re \rightarrow[0,1]$, is defined according to (4), and is depicted in Figure 6. As in (4), the comparison ratios between the success factors $i$ and $j$ are characterized with TFN which describes the judgment about $a_{i j}$ and are denoted by $\tilde{a}_{i j}$. Hence it is possible to describe some degree of vague or ambiguous human perception and decision in pairwise comparisons. In Figure 6(a), a TFN is denoted by either $\left(m_{1} / m_{2}, m_{2} / m_{3}\right)$ or $\left(m_{1}, m_{2}, m_{3}\right)$. For a fuzzy event, the parameters $m_{1}, m_{2}$, and $m_{3}$ in Figure 6(a), respectively, denote the smallest possible value, the most promising value, and the largest possible value. Each TFN has linear representations on its left and right sides such that its membership function can generally be defined as follows:

$$
\mu_{\widetilde{A}}(x)= \begin{cases}\left(x-\frac{l}{m}-l\right), & l \leq x \leq m, \\ \left(u-\frac{x}{u}-m\right), & m \leq x \leq u, \\ 0, & \text { otherwise, }\end{cases}
$$

where $l\left(=m_{1}\right)$ and $u\left(=m_{3}\right)$, respectively, represent the lower and upper bounds of the fuzzy number $\widetilde{A}$, while $m$ (= $m_{2}$ ) is the median value as shown in Figure 6(a). Thus a TFN is generally denoted by $\widetilde{A}=(l, m, u)$.

As shown in Figure 6(a), a fuzzy number can be given by its corresponding left and right representation of each degree of membership, defined by

$$
\begin{aligned}
\widetilde{A} & =\left(A^{l(y)}, A^{r(y)}\right) \\
& =\left(m_{1}+\left(m_{2}-m_{1}\right) y, m_{3}+\left(m_{2}-m_{3}\right) y\right), \\
& \forall y \in[0,1],
\end{aligned}
$$

where $l(y)$ and $r(y)$ denote the left side representation and the right side representation of a fuzzy number, respectively. Matrix $\widetilde{A}$ represents an $(n \times n)$ judgment matrix containing TFNs $\left(\widetilde{a}_{i j}\right)$ for all $i, j \in\{1,2, \ldots, n\}$, as expressed in the following:

$$
\widetilde{A}=\left(\widetilde{a}_{i j}\right)=\left[\begin{array}{cccc}
(1,1,1) & \tilde{a}_{12} & \cdots & \tilde{a}_{1 n} \\
\widetilde{a}_{21} & (1,1,1) & \cdots & \widetilde{a}_{2 n} \\
\vdots & \vdots & \vdots & \vdots \\
\tilde{a}_{n 1} & \tilde{a}_{n 2} & \cdots & (1,1,1)
\end{array}\right] .
$$


TABle 3: (a) Fuzzy linguistic variables and corresponding fuzzy numbers. (b) Fuzzy number memberships of pairwise comparisons [8].

(a)

\begin{tabular}{|c|c|c|c|}
\hline Linguistic variable & Fuzzy number & Membership function & Definition \\
\hline Equally important & $\tilde{1}$ & $(1,1,2)$ & $\begin{array}{l}\text { Practical knowledge and experience imply } \\
\text { that factor } i \text { is equally important when } \\
\text { compared to factor } j \text {. }\end{array}$ \\
\hline Moderately important & $\tilde{3}$ & $(2,3,4)$ & $\begin{array}{l}\text { Practical knowledge and experience imply } \\
\text { that factor } i \text { is moderately more important } \\
\text { when compared to factor } j \text {. }\end{array}$ \\
\hline More important & $\widetilde{5}$ & $(4,5,6)$ & $\begin{array}{l}\text { Practical knowledge and experience imply } \\
\text { that factor } i \text { is more important when } \\
\text { compared to factor } j \text {. }\end{array}$ \\
\hline Strongly important & $\tilde{7}$ & $(6,7,8)$ & $\begin{array}{l}\text { Practical knowledge and experience imply } \\
\text { that factor } i \text { is strongly important when } \\
\text { compared to factor } j \text {. }\end{array}$ \\
\hline Extremely important & $\widetilde{9}$ & $(8,9,9)$ & $\begin{array}{l}\text { Practical knowledge and experience imply } \\
\text { that factor } i \text { is extremely important when } \\
\text { compared to factor } j \text { and totally outweighs } \\
\text { it. }\end{array}$ \\
\hline
\end{tabular}

(b)

\begin{tabular}{cccc}
\hline$a$ & Fuzzy number & $\tilde{a}$ & Fuzzy number \\
\hline 1 & $(1,1,2)$ & 0.50 & $(0.33,0.5,1)$ \\
2 & $(1,2,3)$ & 0.33 & $(0.25,0.33,0.5)$ \\
3 & $(2,3,4)$ & 0.25 & $(0.2,0.25,0.33)$ \\
4 & $(3,4,5)$ & 0.20 & $(0.17,0.2,0.25)$ \\
5 & $(4,5,6)$ & 0.17 & $(0.14,0.17,0.2)$ \\
6 & $(5,6,7)$ & 0.14 & $(0.13,0.14,0.17)$ \\
7 & $(6,7,8)$ & 0.13 & $(0.11,0.13,0.14)$ \\
8 & $(7,8,9)$ & 0.11 & $(0.11,0.11,0.13)$ \\
9 & $(8,9,9)$ & Diagonal elements & $(1,1,1)$ \\
\hline
\end{tabular}

In general, $\tilde{a}_{i j}=\left(l_{i j}, m_{i j}, u_{i j}\right)$, with $l_{i j}$ being the lower limit, $u_{i j}$ the upper limit, and $m_{i j}$ the most likely value, such that $m_{i j}=$ $\sqrt{l_{i j} * u_{i j}}$. Assume that $\widetilde{A}_{1}$ and $\widetilde{A}_{2}$ are two triangular fuzzy numbers with $\widetilde{A}_{1}=\left(l_{1}, m_{1}, u_{1}\right)$ and $\widetilde{A}_{2}=\left(l_{2}, m_{2}, u_{2}\right)$. Some of the fuzzy functional operators (additive, multiplicative, and inverse) are represented in the following:

$$
\begin{aligned}
\widetilde{A}_{1} \oplus \widetilde{A}_{2} & =\left(l_{1}+l_{2}, m_{1}+m_{2}, u_{1}+u_{2}\right), \\
\widetilde{A}_{1} \otimes \widetilde{A}_{2} & =\left(l_{1} l_{2}, m_{1} m_{2}, u_{1} u_{2}\right), \\
\widetilde{A}_{1}^{-1} & =\left(\frac{1}{u_{1}}, \frac{1}{m_{1}}, \frac{1}{l_{1}}\right) .
\end{aligned}
$$

The outcome of each set of pairwise comparisons is expressed as a fuzzy positive reciprocal (9) matrix: $\widetilde{A}=\left\{\widetilde{a}_{i j}\right\}$, such that if $\widetilde{a}_{i j}=1$ then $\widetilde{a}_{i j}=1 / \widetilde{a}_{j i}$ for all $i, j \leq n$, where $n$ denotes the number of alternatives being compared within one set of pairwise comparisons, $\widetilde{a}_{i j}$ denotes the importance of alternative $i$ over alternative $j, \tilde{a}_{j i}$ denotes the importance of alternative $j$ over alternative $i$, and $\widetilde{a}_{i j}=\left(l_{i j}, m_{i j}, u_{i j}\right)$.

The definitions of TFN values in Table 3 are used to facilitate the use of pairwise comparisons in fuzzy based decision processes. TFN ( $\widetilde{a})$ in Table 3 means that the decision maker thinks the importance ratio of two alternatives is about $a$. In Table 3(a), particular linguistic assessment terms called fuzzy linguistic variables are introduced to represent the underlying fuzzy numbers employed for factor evaluations. For this study, five fuzzy linguistic variables are used to capture the subjective judgments about the relative importance of a factor versus another. The linguistic variables are summarized in Table 3(a) as equally important, moderately important, more important, strongly important, and extremely important. In Tables 3(a) and 3(b), a summary of the fuzzy linguistic variable set with lower, most likely, and upper values of underlying TFN and their definitions are given.

After the decision criteria have been determined as depicted in Figure 6(b), a judgment approach for determining the importance levels of these criteria is established. To evaluate the decision judgments, the decision makers select the related linguistic variables; then for calculations they are converted into the TFN and generalized for such analysis as presented in Table 3. The fundamental step in fuzzy AHP methodology is the prioritization procedure, whereby the prioritization problem is defined as deriving the unknown priority vector from the judgment set $\widetilde{A}$. The basic procedure of the fuzzy AHP can be summarized in the following four main steps [33]. 
Step 1 (developing and structuring of the decision hierarchy). This first step comprises the restructuring the complex decision making problem into a hierarchical structure. The derived structural framework is significant in understanding the interactions amongst the elements involved in each decision level and aids the decision makers in exploring the impacts of the different decision components on the evaluation system.

Step 2 (building of the fuzzy pairwise comparison matrices). First, the relative importance of the criteria is determined through pairwise comparison of the decision criteria. After expert evaluations, the relative importance is transformed into triangular fuzzy numbers [25]. By considering a prioritization problem at a decision level with $n$ elements, each set of comparisons for a given level requires $n(n-$ 1)/2 judgments, which are used to construct a positive fuzzy reciprocal comparison matrix $\widetilde{A}=\left\{\widetilde{a}_{i j}\right\}$ as given in (6).

Step 3 (consistency check and fuzzy weights priorities derivation). This step checks for decision consistency and determines the priorities from the pairwise comparison matrices [25]. A fuzzy comparison matrix $\widetilde{A}=\left\{\widetilde{a}_{i j}\right\}$ is consistent if $\tilde{a}_{i k} \otimes \tilde{a}_{k j} \approx \tilde{a}_{i j}$, where $i, j, k=1,2, \ldots, n$ [34]. After the consistency check, the fuzzy priorities $\widetilde{w}_{i}$ are calculated, from which the priority vectors $\left(w_{1}, w_{2}, \ldots, w_{n}\right)^{T}$ are obtained from the comparison matrix by applying a prioritization ranking approach [31].

Step 4 (defuzzification-conversion of the fuzzy weights to crisp weights). Defuzzification can be solved using the graded mean integration representation (GMIR) method by Chen and Hsieh [27] and Hsieh et al. [35]:

$$
\begin{aligned}
& \widetilde{r}_{i}=\left(\widetilde{a}_{i 1} \otimes \cdots \otimes \widetilde{a}_{i j} \otimes \cdots \otimes \widetilde{a}_{i n}\right)^{1 / n}, \\
& \widetilde{w}_{i}=\widetilde{r}_{i} \otimes\left[\widetilde{r}_{1} \oplus \cdots \oplus \widetilde{r}_{i} \oplus \cdots \oplus \widetilde{r}_{n}\right]^{-1},
\end{aligned}
$$

where $\tilde{a}_{i j}$ is fuzzy comparison value of dimension $i$ to criterion $j, \widetilde{r}_{j}$ is a geometric mean of fuzzy comparison value of criterion $i$ to each criterion, and $\widetilde{w}_{i}$ is the fuzzy weight of the $i$ th criterion, which can be indicted by a triangular fuzzy number $\widetilde{w}_{i}=\left(l w_{i}, m w_{i}, u w_{i}\right)[35]$.

Step 5 (calculation and normalization of the weight vector and alternatives ranking). The crisp values are normalized in this stage. This final step aggregates the local priorities obtained at the different levels of the decision structure hierarchy into the composite priorities for the alternatives according to the weighted sum $A_{i}=\sum_{j=1}^{n} w_{j} a_{i j}$, where $w_{j}$ is the weight of criterion $j$. The higher is the value of $A_{i}$, the more preferred is the alternative.

3.3. Fuzzy TOPSIS. The fundamental principle of the TOPSIS method is that the chosen alternative should have the shortest distance from the positive ideal solution (PIS) and the farthest distance from the negative ideal solution (NIS). If in a MCDM problem decision process there are $n$ criteria $\left(C_{1}, C_{2}, \ldots, C_{n}\right)$ amongst $m$ alternatives $\left(A_{1}, A_{2}, \ldots, A_{m}\right)$, then according TOPSIS principle, the performance of the alternative $i$ at the criterion $j$, is such that the best alternative should have the shortest distance from the PIS and the farthest distance from the NIS. The TOPSIS considers the PIS and NIS as the reference points and does not take into consideration the relative importance of the distances from these points [36].

Fuzzy TOPSIS, where TOPSIS refers to Technique for Order Preference by Similarity to Ideal Situation, is a multicriteria decision evaluation method for selected criteria. The principle of TOPSIS approach is that an alternative that is nearest to the Fuzzy Positive Ideal Solution (FPIS) and farthest from the Fuzzy Negative Ideal Solution (FNIS) is chosen as optimal [37, 38].

The following steps give a summary of the fuzzy TOPSIS multicriteria decision making method $[36,39]$.

Step 1 (assignment of ratings to the criteria and the alternatives). If there are $J$ possible candidates denoted by $A=$ $\left\{A_{1}, A_{2}, \ldots, A_{j}\right\}$, to be evaluated against $n$ criteria $C=\left\{C_{1}\right.$, $\left.C_{2}, \ldots, C_{j}\right\}$, and the criteria weights are denoted by $w_{i}\{i=$ $1,2, \ldots, m\}$, then the performance ratings of each decision maker $D_{k}\{k=1,2, \ldots, K\}$ for each alternative $A_{j}\{j=1$, $2, \ldots, n\}$ with respect to criteria $C_{i}\{i=1,2, \ldots, m\}$ are denoted by $\widetilde{R}_{k}=\widetilde{x}_{i j k}(i=1,2, \ldots, m ; j=1,2, \ldots, n ; k=1$, $2, \ldots, K)$ with the membership function $\mu_{\widetilde{R}_{k}}(x)$.

Step 2 (compute and aggregate the fuzzy ratings for the criteria and the alternatives). If the fuzzy ratings of all decision makers are described as triangular fuzzy number $\widetilde{R}_{k}=\left(a_{k}, b_{k}, c_{k}\right)$, then the aggregated fuzzy rating is given by $\widetilde{R}=(a, b, c)$, where $k=1,2, \ldots, K$, where

$$
\begin{aligned}
& a=\min _{k}\left\{a_{k}\right\}, \\
& b=\frac{1}{K} \sum_{k=1}^{K} b_{k}, \\
& c=\max _{k}\left\{c_{k}\right\} .
\end{aligned}
$$

If the fuzzy rating and importance weight of the $k$ th decision maker are $\tilde{x}_{i j k}=\left(a_{i j k}, b_{i j k}, c_{i j k}\right)$ and the corresponding weights are $\widetilde{w}_{i j k}=\left(w_{i 1 k}, w_{i 2 k}, w_{i 3 k}\right)$, then the aggregated fuzzy ratings $x_{i j}$ of the alternatives with respect to each criterion are given by $\tilde{x}_{i j}=\left(a_{i j}, b_{i j}, c_{i j}\right)$, where

$$
\begin{aligned}
& a_{i j}=\min _{k}\left\{a_{i j k}\right\}, \\
& b_{i j}=\frac{1}{K} \sum_{k=1}^{K} b_{i j k}, \\
& c_{i j}=\max _{k}\left\{c_{i j k}\right\} .
\end{aligned}
$$


The aggregated fuzzy weights $\widetilde{w}_{i j}$ of each criterion are then calculated by $\widetilde{w}_{j}=\left(w_{j 1}, w_{j 2}, w_{j 3}\right)$, where

$$
\begin{aligned}
& w_{j 1}=\min _{k}\left\{w_{j k 1}\right\}, \\
& w_{j 2}=\frac{1}{K} \sum_{k=1}^{K} w_{j k 2}, \\
& w_{j 3}=\max _{k}\left\{w_{j k 3}\right\} .
\end{aligned}
$$

Step 3 (compute the fuzzy decision matrix). The fuzzy performance/decision matrix for the alternatives $(\widetilde{D})$ and the criteria $(\widetilde{W})$ is constructed as follows. This is followed by the choice of the appropriate linguistic variables for the alternatives with respect to criteria:

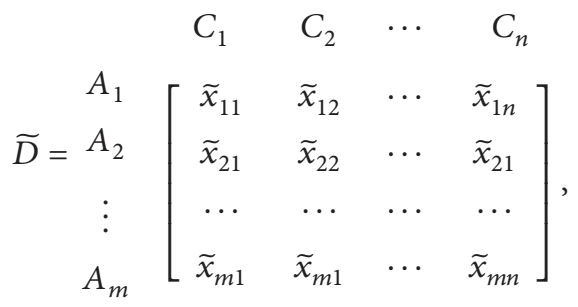

where $\tilde{x}_{i j}=(1 / K)\left(\tilde{x}_{i j}^{1} \oplus \cdots \oplus \tilde{x}_{i j}^{k} \oplus \cdots \oplus \tilde{x}_{i j}^{K}\right)$ with $\widetilde{x}_{i j}^{k}$ being the performance rating of alternative $A_{i}$ with respect to $C_{j}$ as evaluated by the $k$ th decision maker, $\tilde{x}_{i j}^{k}=\left(l_{i j}^{k}, m_{i j}^{k}, u_{i j}^{k}\right)$ and $\widetilde{W}=\left(\widetilde{w}_{1}, \widetilde{w}_{2}, \ldots, \widetilde{w}_{n}\right)[40]$.

Step 4 (normalize the fuzzy decision matrix). The raw data are normalized using linear scale transformation in order to bring the various criteria scales into a comparable scale. The normalized fuzzy decision matrix $\widetilde{R}$ is given by

$$
\widetilde{R}=\left[\widetilde{r}_{i j}\right]_{m \times n}, \quad i=1,2, \ldots, m ; j=1,2, \ldots, n,
$$

where $\tilde{r}_{i j}=\left(a_{i j} / c_{j}^{*}, b_{i j} / c_{j}^{*}, c_{i j} / c_{j}^{*}\right)$ and $c_{j}^{*}=\max _{i} c_{i j}$ are called the benefit criteria and $\widetilde{r}_{i j}=\left(a_{j}^{-} / c_{j}^{*}, a_{j}^{-} / b_{j}^{*}, a_{j}^{-} / a_{j}^{*}\right)$ and $a_{j}^{-}=$ $\min _{i} a_{i j}$ are called the cost criteria.

Step 5 (compute the weighted normalized matrix). The weighted normalized matrix $(\widetilde{V})$ for criteria is computed by multiplying the weights $\left(\widetilde{w}_{j}\right)$ of evaluation criteria with the normalized fuzzy decision matrix $r_{i j}$ :

$$
\begin{aligned}
\widetilde{V}=\left[\widetilde{v}_{i j}\right]_{m \times n}=\left[\widetilde{r}_{i j}(\cdot)\right. & \left.w_{i j}\right], \\
& \quad i=1,2, \ldots, m ; j=1,2, \ldots, n .
\end{aligned}
$$

Step 6 (compute the fuzzy positive ideal solution (FPIS) and fuzzy negative ideal solution (FNIS)). The FPIS and FNIS of the alternatives are computed as follows. From the weighted normalized fuzzy-decision matrix, the elements $\widetilde{v}_{i j}$ are normalized positive TFNs within the closed interval $[0,1]$. Then, FPIS $\left(A^{+}\right)$and FNIS $\left(A^{-}\right)$are calculated [41]:

$$
\begin{aligned}
& A^{+}=\left(\widetilde{v}_{1}^{+}, \widetilde{v}_{2}^{+}, \ldots, \widetilde{v}_{n}^{+}\right), \\
& \text {where } v_{j}^{+}=\max _{i}\left\{v_{i j 3}\right\}, i=1,2, \ldots, m ; j=1,2, \ldots, n, \\
& A^{-}=\left(\widetilde{v}_{1}^{-}, \widetilde{v}_{2}^{-}, \ldots, \widetilde{v}_{n}^{-}\right), \\
& \text {where } v_{j}^{-}=\max _{i}\left\{v_{i j 1}\right\}, i=1,2, \ldots, m ; j=1,2, \ldots, n .
\end{aligned}
$$

Step 7 (compute the distance of each alternative from FPIS and FNIS). The distance $\left(d_{i}^{+}, d_{i}^{-}\right)$of each weighted alternative $i=1,2, \ldots, m$ from the FPIS and the FNIS is computed as follows, using the area compensation method:

$$
\begin{array}{r}
d_{i}^{+}=\sum_{j=1}^{n} d_{v}\left(\widetilde{v}_{i j}, \widetilde{v}_{j}^{+}\right)=\left[\frac{1}{3} \sum_{j=1}^{n}\left(\widetilde{v}_{i j}-\widetilde{v}_{j}^{+}\right)^{2}\right]^{1 / 2}, \\
i=1,2, \ldots, m, \\
d_{i}^{-}=\sum_{j=1}^{n} d_{v}\left(\widetilde{v}_{i j}, \widetilde{v}_{j}^{-}\right)=\left[\frac{1}{3} \sum_{j=1}^{n}\left(\widetilde{v}_{i j}-\widetilde{v}_{j}^{-}\right)^{2}\right]^{1 / 2}, \\
i=1,2, \ldots, m,
\end{array}
$$

where $d_{v}(\tilde{a}, \tilde{b})$ is the distance measurement between two fuzzy numbers $\tilde{a}$ and $\tilde{b}$.

Step 8 (compute the closeness coefficient $\left(\mathrm{CC}_{i}\right)$ of each alternative). The closeness coefficient $\left(\mathrm{CC}_{i}\right)$ or the degree of relative gaps that represents the distances to the fuzzy positive ideal solution $\left(A^{*}\right)$ and the fuzzy negative ideal solution $\left(A^{-}\right)$ is computed. The closeness coefficient of each alternative is calculated as

$$
\mathrm{CC}_{i}=\frac{d_{i}^{-}}{d_{i}^{-}+d_{i}^{+}}=\left(1-\frac{d_{i}^{+}}{d_{i}^{-}+d_{i}^{+}}\right)
$$

$$
\text { for } i=1,2, \ldots, m \text {, }
$$

where $d_{i}^{-} /\left(d_{i}^{-}+d_{i}^{+}\right)$is the fuzzy satisfaction degree in the $i$ th alternative and $d_{i}^{+} /\left(d_{i}^{-}+d_{i}^{+}\right)$is the fuzzy gap degree in the $i$ th alternative.

Step 9 (ranking the alternatives). In the last step, the different alternatives are ranked according to the closeness coefficient $\left(\mathrm{CC}_{i}\right)$ in decreasing order. The best alternative is closest to the FPIS and farthest from the FNIS.

\section{Case Study Results and Analysis}

4.1. GIS-SQL Database for Thematic Displays of Pavement Distress Data. Figure 7 shows the typical output of the results for the GIS-SQL based graphical thematic display of the road condition survey for the Nandi road distress between segments $2100 \mathrm{~m}$ and $2400 \mathrm{~m}$. The segment query results 
TABLE 4: Case study maintenance functions for the observed distresses.

\begin{tabular}{|c|c|c|c|c|c|c|c|}
\hline $\begin{array}{l}\text { Distress treatment (maintenance function) for } \\
\text { observed distress }\end{array}$ & Fog seal & $\begin{array}{c}\text { Micro } \\
\text { surfacing }\end{array}$ & $\begin{array}{c}\text { Slurry } \\
\text { seal }\end{array}$ & $\begin{array}{c}\text { Cape } \\
\text { seal }\end{array}$ & Chip seal & $\begin{array}{c}\text { Thin HMA } \\
\text { overlay }\end{array}$ & Resurfacing \\
\hline Rutting & & $x$ & & & & $x$ & \\
\hline Alligator and block cracking & $\times$ & $x$ & & $x$ & $x$ & $\times$ & $x$ \\
\hline Longitudinal and transverse cracking & & $\times$ & & $\times$ & $\times$ & $\times$ & \\
\hline Pothole & & $\times$ & & & & $\times$ & $\times$ \\
\hline Raveling & $x$ & $x$ & $x$ & $x$ & $x$ & & \\
\hline Resurfacing & & $x$ & & & & $x$ & $x$ \\
\hline
\end{tabular}

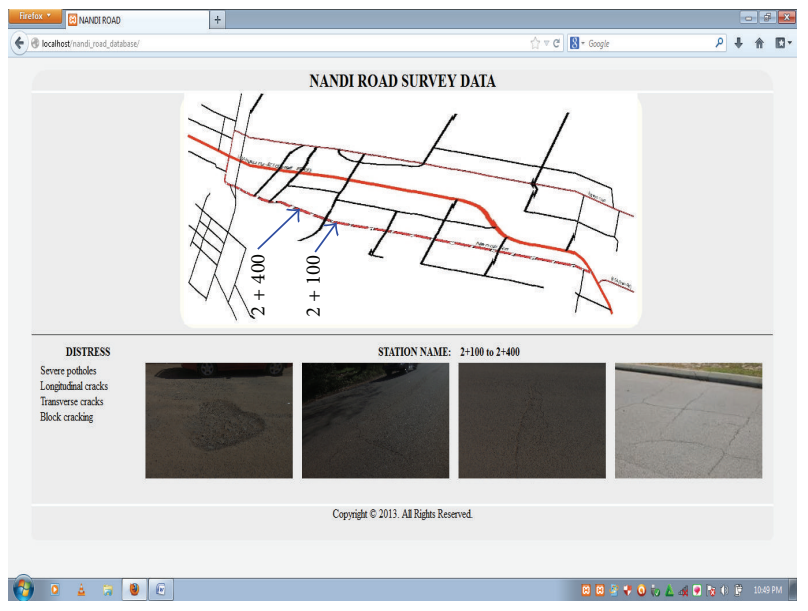

FIgURE 7: An SQL based thematic graphical display of road pavement distress at specified segments.

display the following information regarding the segment: the chainage of the road segment surveyed, the distresses observed within the segment, and the distress images. Such pavement condition data representation can easily be leveraged into a web access platform, so as to be easily accessible to the different levels of urban road maintenance and management.

A summary statistic on the frequency of occurrence of distress types is also generated for the entire surveyed road pavement as presented in Figure 8. Results in Figure 8 show the most and least frequent distresses on the road as longitudinal cracks and patching, respectively. A plot of the degree of distress that is low, medium, or high can also be derived from the empirically observed and categorized severity of distresses, though such linguistic information is captured in the distress survey by the condition assessment experts.

4.2. Case Study Road Maintenance Treatments. From the observed distresses presented in Table 1 and in Figure 5, the possible maintenance treatments and functions are determined, with the results presented in Table 4. From the condition survey results, it was observed that there were seven main pavement distresses or maintenance functions along the $3 \mathrm{~km}$ road. From the results in Table 4 it was noted that if the distresses identified in the pavement condition survey are related to structural deficiencies, then the road

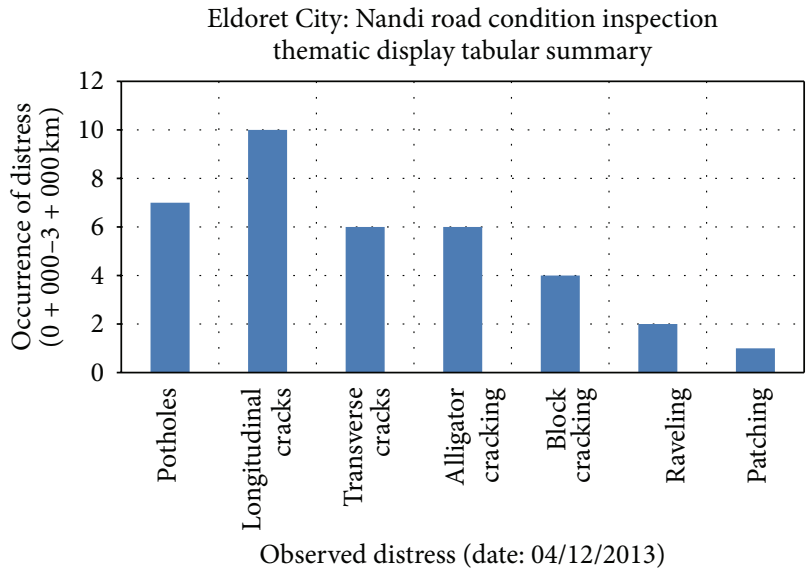

FIGURE 8: Summary of the distresses report of for the case study.

section is most likely not to be a candidate for a preventive basic maintenance treatment but rather for rehabilitation.

The results in Table 4 are summarized as follows: (i) fog seal: it is an application of diluted emulsion (normally 1 to 1) to enrich the pavement surface and hinder raveling and oxidation and is considered as a temporary application; (ii) crack sealing: this treatment is used to prevent water and debris from entering cracks in the pavement; the treatment might include routing to clean the entire crack and to create a reservoir to hold the sealant; (iii) chip seal: this treatment is used to waterproof the surface, seal small cracks, and improve friction; although it is typically used on low volume roads and streets, it can also be used on high volume roads and highways; (iv) thin cold mix seals: these treatments include slurry seals, cape seals, and micro surfacing which are used on all types of facilities to fill cracks, improve friction, and improve ride quality; (v) Thin Hot Mix Asphalt (HMA) overlays: these include dense-, open-, and gap-graded mixes (as well as surface recycling) that are used to improve ride quality, provide surface drainage and friction, and correct surface irregularities; Thin HMA overlays are generally $37 \mathrm{~mm}$ in thickness; and (vi) resurfacing: resurfacing of a road pavement in totality or section thereof is normally carried out in order to add strength to the asphalt layer and to prolong its life and or to correct a specific section or the entire surface profile and in order to improve on the riding quality and surface water drainage. 
TABLE 5: Round 1 of decision based on importance of allocation or weighting.

\begin{tabular}{lccccccccccccc}
\hline \multirow{2}{*}{ Road pavement maintenance objectives } & \multicolumn{1}{c}{ Pavement expert (engineer/inspector/planner) } & Maintenance relative weights \\
& 1 & 2 & 3 & 4 & 5 & 6 & 7 & 8 & 9 & 10 \\
Road safety & 35 & 45 & 45 & 30 & 40 & 45 & 35 & 50 & 30 & 35 & 0.39 \\
Pavement surface preservation & 40 & 30 & 20 & 40 & 30 & 25 & 30 & 20 & 30 & 40 & 0.31 \\
Road operational status and standards & 15 & 15 & 20 & 20 & 15 & 20 & 25 & 20 & 20 & 15 & 0.19 \\
Road aesthetics & 10 & 10 & 15 & 10 & 15 & 10 & 10 & 10 & 10 & 10 & 0.11 \\
\hline
\end{tabular}

TABLE 6: Round 2 of judgment based on incremental linear ranking with 1.0 as the lowest importance.

\begin{tabular}{lcccccccccccc}
\hline \multirow{2}{*}{ Road pavement maintenance objectives } & \multicolumn{4}{c}{ Pavement expert (engineer/inspector/planner) } & \multicolumn{3}{c}{ Maintenance relative weights based } \\
& 1 & 2 & 3 & 4 & 5 & 6 & 7 & 8 & 9 & 10 & on linear scale \\
\hline Road safety & 3 & 4 & 5 & 5 & 4 & 2 & 2 & 2.5 & 4 & 4 & 0.36 \\
Pavement surface preservation & 2.5 & 3 & 3 & 4 & 4 & 3 & 2 & 4 & 3 & 2 & 0.30 \\
Road operational status and standards & 2 & 3 & 3 & 4 & 3 & 1.5 & 2 & 3 & 3 & 1 & 0.25 \\
Road aesthetics & 1 & 1 & 1 & 1 & 1 & 2 & 1 & 1 & 1 & 1 & 0.12 \\
\hline
\end{tabular}

TABLE 7: Round 3 of decision according to crisp scale based ranking (with 1 being the least important and 5 the most important).

\begin{tabular}{lccccccccccc}
\hline \multirow{2}{*}{ Road pavement maintenance objectives } & \multicolumn{1}{c}{ Pavement } & \multicolumn{1}{c}{ Maintenance relative weights based } \\
& 1 & 2 & 3 & 4 & 5 & 6 & 7 & 8 & 9 & 10 & on 1-5 crisp scale \\
\hline Road safety & 5 & 5 & 4 & 5 & 5 & 4 & 5 & 5 & 5 & 5 & 0.39 \\
Pavement surface preservation & 4 & 4 & 3 & 4 & 5 & 4 & 4 & 5 & 4 & 4 & 0.32 \\
Road operational status and standards & 3 & 2 & 3 & 3 & 4 & 3 & 2 & 3 & 2 & 3 & 0.22 \\
Road aesthetics & 1 & 1 & 1 & 1 & 1 & 2 & 1 & 1 & 1 & 1 & 0.07 \\
\hline
\end{tabular}

4.3. Maintenance Objectives Determination, Weighting, and AHP Hierarchical Structure. To determine the maintenance objectives, from the maintenance functions, ten experts comprising pavement engineers, inspectors, and transport planners from Kenya Urban Roads Authority (KURA) gave their assessments and judgments on the maintenance objectives weighting for routine urban road maintenance. This was carried out by first selecting the maintenance objectives, where the experts were asked to nominate a number of maintenance objectives based on the observed distresses (Table 4). From the expert evaluation results, the top four maintenance objectives are adopted as the case study maintenance criteria.

The selected road maintenance objectives were determined, respectively, as road safety (RS); pavement surface preservation (PSR); road operational status and standards (ROS) or quality; and road aesthetics (RA) (Table 5). After the maintenance objectives are obtained, the weights of the selected maintenance objectives are then determined.

The same group of experts gave their estimates on the four maintenance objectives weighting. Each of the experts assigned weights to the maintenance objectives in three rounds, each round using a different approach comprising the following elements. The rationale of using the three rounds is to vary and objectively, without biases, determine the weights based on different ranking scales, from percentages, incremental decimals linear scale (1.0-5.0), and whole number linear scale (1-5).

(i) Round 1: in this round weighting is carried out in terms of percentages and applied to each maintenance objective. (ii) Round 2: by using linear incremental scale with steps of 0.25 , the objective with the lowest importance is set at 1.0 and the one with the greatest importance is recorded at 5.0, depending on the function.

(iii) Round 3: on a linear scale of crisp values of 1-5 (increasing at intervals of 1), the importance of the objectives is ranked with 1 representing the least important objective and 5 representing the most important.

Because of human objectivity, reasoning, and subjectivity, at the end of three rounds, the results will vary based on the individual decision maker's perception of the criterion and in accordance with ranking scale used. At the end, the results are aggregated to minimize on subjectivity and to objectively determine the overall weights. Results for the three ranking steps are presented in Tables 5-7 for the four maintenance objectives. In the pavement expert columns, 1 to 10 represent the ten decision experts.

From the averaged AHP and fuzzy weights based evaluation matrices represented, respectively, in Tables 8 and 9, the final aggregated weighting vector was determined as $W=$ $[0.37,0.31,0.22,0.10]^{T}$ for the four maintenance objectives and is presented in Table 10. The results in Table 10 show that, according to the experts, road safety and surface condition accounted for $68 \%$ of the maintenance objectives preferences, while quality and aesthetics together contributed to $32 \%$ of the maintenance preferences.

From the above results the final AHP hierarchical structure of the maintenance prioritization levels is derived for 
TABLE 8: Averaged AHP based evaluation matrix for the maintenance objectives.

\begin{tabular}{lcccc}
\hline Road maintenance objectives & Road safety & $\begin{array}{c}\text { Pavement surface } \\
\text { preservation }\end{array}$ & $\begin{array}{c}\text { Operational status } \\
\text { and standards }\end{array}$ & $\begin{array}{c}\text { Road aesthetics } \\
\text { Road safety }\end{array}$ \\
Pavement surface preservation & 0.5 & 2 & 1 & 0.5 \\
Operational status and standards & 1 & 1 & 1 & 0.75 \\
Road aesthetics & 0.5 & 2 & 1 & 1 \\
\hline
\end{tabular}

TABLE 9: Equivalent fuzzy based evaluation matrix for maintenance objectives.

\begin{tabular}{|c|c|c|c|c|}
\hline Road maintenance objectives & Road safety & $\begin{array}{c}\text { Pavement surface } \\
\text { preservation }\end{array}$ & $\begin{array}{l}\text { Operational status } \\
\text { and standards }\end{array}$ & Road aesthetics \\
\hline Road safety & $(1,1,1)$ & $(1.33,2,4)$ & $(0.8,1,1.33)$ & $(1,2,3)$ \\
\hline Pavement surface preservation & $(0.33,0.5,0.75)$ & $(1,1,1)$ & $(0.25,0.5,1)$ & $(0.5,0.75,1)$ \\
\hline Operational status and standards & $(0.75,1,1.25)$ & $(1,2,3)$ & $(1,1,1)$ & $(0.5,1,1.25)$ \\
\hline Road aesthetics & $(0.33,0.5,1)$ & $(1,1.33,2)$ & $(0.8,1,1.33)$ & $(1,1,1)$ \\
\hline
\end{tabular}

TABLE 10: Average maintenance objectives weighting vector $(W)$ for the case study.

\begin{tabular}{|c|c|c|c|c|}
\hline Road maintenance objectives & Road safety & $\begin{array}{l}\text { Pavement surface } \\
\text { preservation }\end{array}$ & $\begin{array}{l}\text { Operational status } \\
\text { and standards }\end{array}$ & Road aesthetics \\
\hline $\begin{array}{l}\text { Mean relative maintenance } \\
\text { objective weights }\end{array}$ & 0.37 & 0.31 & 0.22 & 0.10 \\
\hline
\end{tabular}

the case study as presented in Figure 9. As already stated, hierarchical structuring of a pavement maintenance prioritization problem is an efficient way of dealing with the decision complexity and is useful in identifying the major components of the PMMS. From Figure 9, it is seen that the structure for the case study comprises three levels, with the final level being the overall goal, and the other two levels: the first, lower hierarchy, is the maintenance functions, and the second, higher hierarchy, is the maintenance objectives. For realistic cost-benefit evaluation, every $M \& R$ project should have its own hierarchical structure.

4.4. Multiattribute Analysis for Pairwise Comparisons of Maintenance Objectives. For the pairwise comparative evaluation, ten pavement engineers from KURA gave their judgments using pairwise comparisons of the four maintenance objectives. All the ten engineers gave pairwise comparisons to the seven maintenance functions with respect to the predetermined four maintenance objectives. The pairwise comparisons are based on nine-point Saaty scale of relative importance [26] as presented in Table 2. Using the fuzzification and defuzzification rules as presented in Table 3, substitutes for the crisp numbers and the fuzzy numbers are obtained.

The optimal level of confidence is the degree of accuracy with which one is able to execute a given decision making task. That is, due to the subjective nature of the exercise, an optimal level from experienced researchers is empirically considered to be neither too high nor too low, and therefore a value above mean threshold of $60 \%$ is chosen. On the other hand, the attitude towards risk is the effect of executing the particular task within an error margin. For this case study, the error margin for the decision makers is set a maximum of $50 \%$ chance, and the errors are attributed to mistakes (gross), systematic and random occurrences. This means that an optimal performer should be able to execute the task with an accuracy of at least $60 \%$ and is liable to maximum error level of $50 \%$.

By choosing an optimal level of confidence of ( $\alpha=60 \%)$ and assuming a moderate attitude to risk of $(\lambda=0.5)$, the fuzzy performance matrix $(Z)$ is defuzzified, under the optimal boundary conditions of $[\alpha=0.6, \lambda=0.5]$. The matrix is normalized to satisfy the condition that the summation of all the seven maintenance functions under each criterion is 1 . Therefore the crisp normalized performance matrix $Z_{\alpha}^{\lambda}$ is obtained as below for the four pavement maintenance objectives and as determined by the ten experts:

$$
Z_{\alpha}^{\lambda}=\left|\begin{array}{cccc}
(0.199) & (0.428) & (0.349) & (0.349) \\
(0.464) & (0.415) & (0.377) & (0.064) \\
\ldots & \ldots & \ldots & \ldots \\
(0.170) & (0.142) & (0.161) & (0.229)
\end{array}\right|
$$

The final maintenance functions ranking is then derived and the results are presented in Tables 11 and 12 for fuzzy AHP and fuzzy TOPSIS. The final performance index for each maintenance function is obtained by averaging the respective priorities as determined by each of the decision makers. It is observed that the results in Tables 11 and 12 are nearly the same except for the rakings 5 and 6 . Compared with the manual-based evaluations and ranking, which are based on the set out guiding principles such distress type, the dimensions (area, length, and depth), and significance of the road, for the aggregation of individual ranking of each 


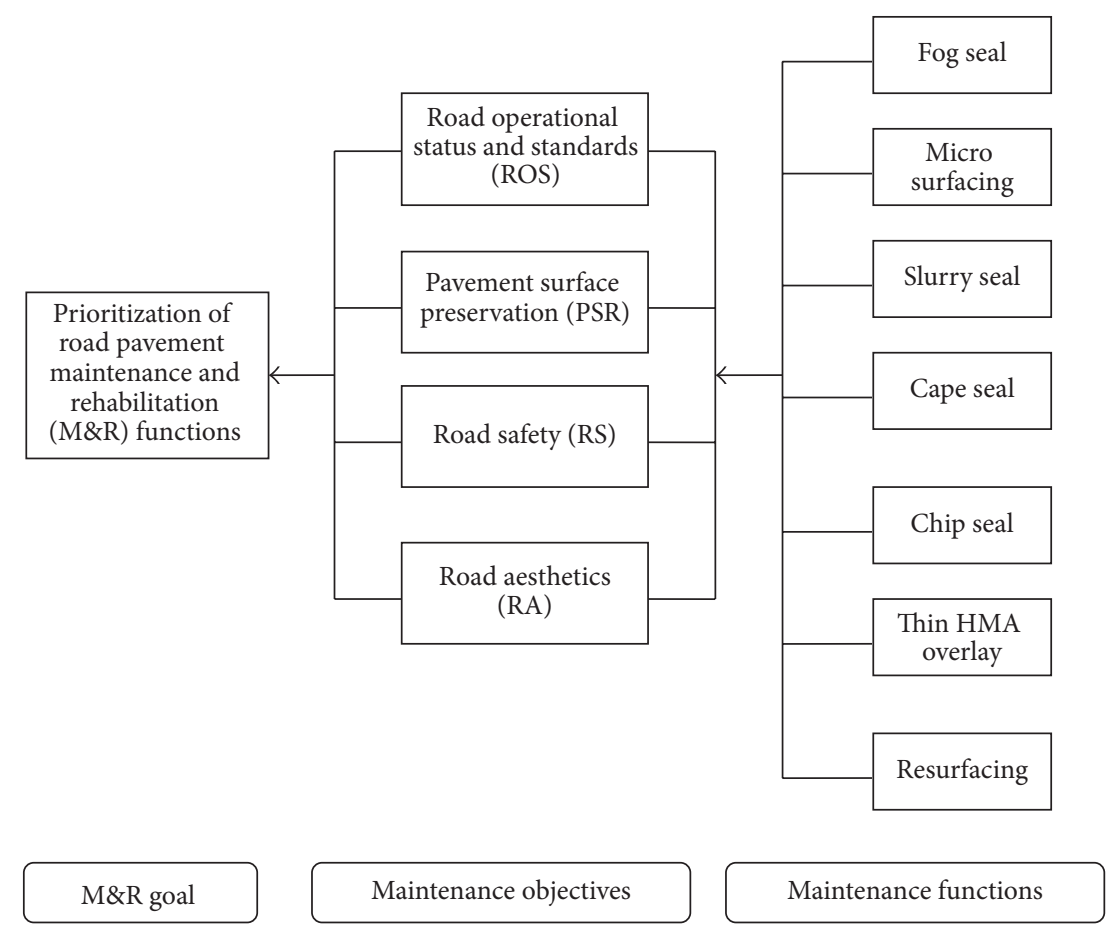

FIGURE 9: Three-level hierarchical structure of maintenance function prioritization process for the case study road.

TABLE 11: Maintenance function ranking and performance ranking using fuzzy AHP.

\begin{tabular}{lccc}
\hline Function number & $\begin{array}{c}\text { Maintenance } \\
\text { function }\end{array}$ & $\begin{array}{c}\text { Performance } \\
\text { index }\end{array}$ & Ranking index \\
\hline 1 & Fog seal & 0.755 & 7 \\
2 & Micro & 0.798 & 6 \\
3 & surfacing & 0.870 & 3 \\
4 & Slurry seal & 0.816 & 5 \\
5 & Cape seal & 0.852 & 4 \\
6 & Chip seal & 0.883 & 1 \\
7 & Thin HMA & overlay & 2 \\
\hline
\end{tabular}

distress and scoring, the fuzzy TOPSIS results in Table 12 were found to be consistent with the prioritization experiences in practice. The top three maintenance functions (Thin HMA overlay, resurfacing, and slurry seal) are all pavement related functions and are related to the pavement deficiencies and have more direct impacts on the road pavement functions.

\section{Comparison of Fuzzy AHP and Fuzzy TOPSIS Results}

To compare variance in the decisions, the fuzzy AHP and fuzzy TOPSIS were plotted on the same scale, by rescaling the performance indices of all the seven maintenance functions to the same scale such that the normalized sum equals 1 . Figure 10 presents the results of the comparative ranking indices. The results in Figure 10 show that the fuzzy AHP tends to overestimate the ranking process as compared to the fuzzy TOPSIS and the manual-based decision validation procedure. The results in Figure 10 show that the fuzzy TOPSIS results are quite close to manual-based approach, which implies that the TOPSIS approach is much more able to capture the user degree of confidence. Nonetheless, different case studies can be carried out in order to generalize the effectiveness of two fuzzy based prioritization techniques, especially in different geographical regions.

There are however similarities and differences in the rankings as obtained from the two prioritization techniques as seen in Figure 10. For example, the top three maintenance functions are the same and only in the bottom three is there a slight difference. The results also show that there is consistency in the fuzzy TOPSIS ranking process, as compared to the variability in ranking values in fuzzy AHP.

Although fuzzy AHP and fuzzy TOPSIS have the same objective of prioritizing the maintenance objectives and functions through MCDM principles, they have fundamental differences. According to fuzzy AHP, pairwise comparisons by decision makers are made for the criteria and alternatives under each criterion. The resulting comparisons are integrated and decision makers' pairwise comparison values are transformed into triangular fuzzy numbers. The priority weights of the criteria and alternatives are then derived. According to the combination of the priority weights of criteria and alternatives, the best alternative is determined.

In fuzzy TOPSIS, the decision makers use the linguistic variables to evaluate each alternative with respect to each criterion in order to assess the importance of the criteria. The linguistic variables are converted into triangular 
TABLE 12: Maintenance function ranking and performance index ranking using fuzzy TOPSIS.

\begin{tabular}{|c|c|c|c|c|c|}
\hline Function number & Maintenance function & $D_{\alpha}^{\lambda+}$ & $D_{\alpha}^{\lambda-}$ & $\begin{array}{c}\text { Separation score } \\
\mathrm{CC}_{i}\end{array}$ & Ranking \\
\hline 1 & Fog seal & 0.0580 & 0.0220 & 0.2750 & 7 \\
\hline 2 & Micro surfacing & 0.0497 & 0.0485 & 0.4255 & 5 \\
\hline 3 & Slurry seal & 0.0310 & 0.0270 & 0.4655 & 3 \\
\hline 4 & Cape seal & 0.0459 & 0.0340 & 0.3921 & 6 \\
\hline 5 & Chip seal & 0.0378 & 0.0291 & 0.4350 & 4 \\
\hline 6 & Thin HMA overlay & 0.0347 & 0.0420 & 0.5480 & 1 \\
\hline 7 & Resurfacing & 0.0432 & 0.0477 & 0.5248 & 2 \\
\hline
\end{tabular}

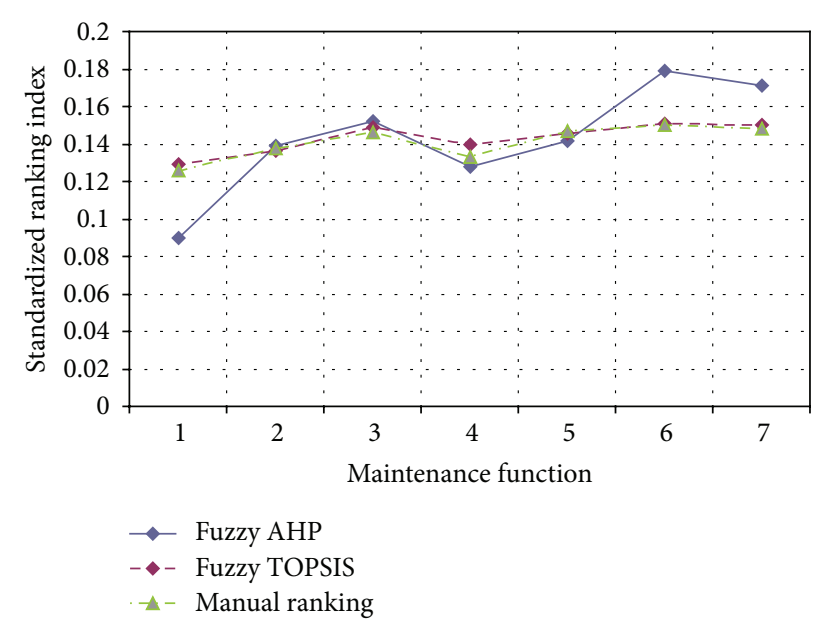

FIGURE 10: Comparison of maintenance prioritization results from fuzzy AHP and fuzzy TOPSIS.

fuzzy numbers, from which the fuzzy decision matrix is determined. The normalized fuzzy decision matrix and the weighted normalized fuzzy decision matrix are then formed. After determining the FPIS and FNIS, the distance (d) of each alternative to FPIS and FNIS is also determined. Therefrom the closeness coefficient of each alternative is individually computed. From the seven alternatives, the closeness coefficient revealed the results in Table 12 for the fuzzy TOPSIS and in Table 11 for the fuzzy AHP.

The fundamental differences between these two methods could be based on the fact that TOPSIS considers the linguistic variables at the onset of the pairwise comparison and therefore the results are not affected by the AHP drawbacks in fuzzy AHP. Nonetheless, according to the results, the top three results were similar for both methods. This in part shows that, apart from the subjectivity that is not critically captured by AHP in the pairwise comparison process, both TOPSIS and AHP as multicriteria decision making techniques are completive in performance. But, as presented in Figure 10, the subjectivity in AHP is noticed when the results are compared on standardized scale.

In overall, the appropriate preventive maintenance strategy will largely be influenced by the type, severity, and extent of the pavement surface distresses and the structural and functional condition of the pavement. In this regard, the influences of the categories of pavement maintenance and the performance of preventive maintenance treatments, as recommended by Johanns and Craig [42], should be taken into consideration in balancing between preventive, corrective, and emergency maintenances schedules.

\section{Conclusions}

The current case study presents a methodological overview on the use of multiattribute decision making using fuzzy AHP and fuzzy TOPSIS for the prioritization of pavement maintenance alternatives. By using different sets of fuzzy membership functions, the current approach enables decision makers to capture the often unpredictable and complex pavement maintenance prioritization procedure, in a more objective way.

For the case study, it is observed that maintenance measures relate to the following pavement failures: cracking, potholes, raveling, and patching. From the prioritization results, and with manual-based opinion, it is concluded that the top three maintenance objective functions in the case study urban roads are characterized by Thin HMA overlay, resurfacing, and slurry seals, for the following pavement maintenance objectives: road safety conditions, pavement surface preservation, road operational status and standards, and the road aesthetics. The results show that road safety is closely related to the actual pavement preservation status, and both contribute in nearly the same ratio to more than $60 \%$ of the maintenance objectives.

The ranking procedures yielded nearly similar results, with fuzzy TOPSIS performing slightly better than fuzzy AHP, when the results were compared against actual empirical-manual-based prioritization. Further, the results show that, at optimal degrees of confidence and risk, the fuzzy AHP tended to overestimate the prioritization ranking process, as compared to the fuzzy TOPSIS approach.

To improve on the current study, it is recommended that automated distress surveys and measurements be considered. This is important in improving on the speeds of condition surveys, accuracy and reliability, and cost-effectiveness. Developments on pavement maintenance prioritization approach that can enable decision makers to quantify and minimize the total risk due to canceling or deferring maintenance functions during budget cuts should also be considered in the prioritization process. Additionally, studies on the 
spatial-temporal modelling of the rate of pavement deterioration are recommended in order to integrate the maintenance prioritization approach with the asset's whole-life economic analysis. And, in addition, detailed studies on the variations and relationships between the decision makers' level of confidence and attitude to risk in multicriteria decision making process can also be a detailed subject of investigation.

\section{Conflict of Interests}

The authors declare that there is no conflict of interests regarding the publication of this paper.

\section{Acknowledgments}

The authors would like to acknowledge all those who were involved in the field surveys on the road condition inspection project. Further acknowledgements go to the contributions in terms of comments by the anonymous reviewers who took their time to pinpoint key areas to improve on in this paper.

\section{References}

[1] L. Sun and W. Gu, "Pavement condition assessment using fuzzy logic theory and analytic hierarchy process," Journal of Transportation Engineering, vol. 137, no. 9, pp. 648-655, 2011.

[2] S. Cafiso, A. Graziano, and S. Battiato, "Evaluation of pavement surface distress using digital image collection and analysis," in Proceedings of the 7th International Congress on Advances in Civil Engineering, p. 10, Yildiz Technical University, Istanbul, Turkey, October 2006.

[3] Y. U. Shah, S. S. Jain, and M. Parida, "Evaluation of prioritization methods for effective pavement maintenance of urban roads," International Journal of Pavement Engineering, vol. 15, no. 3, pp. 238-250, 2014.

[4] T. L. Saaty, "A scaling method for priorities in hierarchical structures," Journal of Mathematical Psychology, vol. 15, no. 3, pp. 234-281, 1977.

[5] T. L. Saaty, Multi-Criteria Decision Making: The Analytic Hierarchy Process, McGraw-Hill, New York, NY, USA, 1980.

[6] P. K. Agarwal, A. Das, and P. Chakroborty, "A rational approach of prioritization of highway sections for maintenance," in Proceedings of the 6th International Conference on Managing Pavements, p. 12, Brisbane, Australia, October 2004.

[7] J. Farhan and T. F. Fwa, "Pavement maintenance prioritization using analytic hierarchy process," Transportation Research Record, vol. 2093, pp. 12-24, 2009.

[8] W. Liu and Z. Zhang, "Prioritization of highway maintenance functions using multi-attribute decision making with fuzzy pairwise comparison," Tech. Rep. SWUTC/11/161128-1, Center for Transportation Research, University of Texas, Austin, Tex, USA, 2012.

[9] H. Deng, "Multi-criteria analysis with fuzzy pairwise Comparison," International Journal of Approximate Reasoning, vol. 21, no. 3, pp. 215-231, 1999.

[10] L. A. Zadeh, "Fuzzy sets," Information and Computation, vol. 8, pp. 338-353, 1965.

[11] J. Efstathiou, "Practical multi-attribute decision-making and fuzzy set theory," in TIMS/Studies in Management Science, vol. 20, pp. 307-320, Elsevier, 1984.
[12] D. Dubois and H. Prade, "Recent models of uncertainty and imprecision as a basis for decision theory toward less normative frameworks," in Intelligent Decision Support in Process Environments, E. Hollnagel, G. Mancini, and D. Woods, Eds., pp. 3-24, Springer, Berlin, Germany, 1985.

[13] S. J. Chen and C. L. Hwang, Fuzzy Multiple Attribute Decision Making: Methods and Applications, Springer, New York, NY, USA, 1992.

[14] H.-J. Zimmermann, Fuzzy Set Theory and Its Applications, Kluwer Academic, Boston, Mass, USA, 1996.

[15] M. Kordi and S. A. Brandt, "Effects of increasing fuzziness on analytic hierarchy process for spatial multicriteria decision analysis," Computers, Environment and Urban Systems, vol. 36, no. 1, pp. 43-53, 2012.

[16] L. Mikhailov, "Deriving priorities from fuzzy pairwise comparison judgements," Fuzzy Sets and Systems, vol. 134, no. 3, pp. 365385, 2003.

[17] D. Moazami and R. Muniandy, "Fuzzy inference and multicriteria decision making applications in pavement rehabilitation prioritization," Australian Journal of Basic and Applied Sciences, vol. 4, no. 10, pp. 4740-4748, 2010.

[18] C. L. Hwang and K. Yoon, Multiple Attribute Decision Making: Methods and Applications. A State-of-the-Art Survey, Springer, New York, NY, USA, 1981.

[19] C. L. Hwang and K. S. Yoon, Multiple Attribute Decision Making: Methods and Applications, Springer, Berlin, Germany, 1981.

[20] A. Vega, J. Aguarón, J. García-Alcaraz, and J. M. MorenoJiménez, "Notes on dependent attributes in TOPSIS," Procedia Computer Science, vol. 31, pp. 308-317, 2014.

[21] K. C. P. Wang, C. Nunn, C. Mackey et al., "Network level crack survey with the automated real-time distress analyzer," in Proceedings of the 83rd Annual Meeting of Transportation Research Board (TRB '03), CD-ROM, p. 22, 2003.

[22] N. Bandara and M. Gunaratne, "Current and future pavement maintenance prioritization based on rapid visual condition evaluation," Journal of Transportation Engineering, vol. 127, no. 2, pp. 116-123, 2001.

[23] F. Zahedi, "The analytic hierarchy process: a survey of the method and its applications," Interfaces, vol. 16, no. 4, pp. 96108, 1996.

[24] O. S. Vaidya and S. Kumar, "Analytic hierarchy process: an overview of applications," European Journal of Operational Research, vol. 169, no. 1, pp. 1-29, 2006.

[25] Y. Ouma and R. Tateishi, "Urban flood vulnerability and risk mapping using integrated multi-parametric AHP and GIS: methodological overview and case study assessment," Water, vol. 6, no. 6, pp. 1515-1545, 2014.

[26] T. L. Saaty, "Decision making with analytic hierarchy process," International Journal of Services Sciences, vol. 1, no. 1, pp. 83-98, 2008.

[27] S. H. Chen and C. H. Hsieh, "Representation, ranking, distance, and similarity of L-R type fuzzy number and application," Australian Journal of Intelligent Information Processing Systems, vol. 6, no. 4, pp. 217-229, 2000.

[28] M. T. Tang, G. H. Tzeng, and S. W. Wang, "A hierarchy fuzzy MCDM method for studying electronic marketing strategies in the information service industry," Journal of International Information Management, vol. 8, no. 1, pp. 1-22, 1999.

[29] D.-Y. Chang, "Applications of the extent analysis method on fuzzy AHP," European Journal of Operational Research, vol. 95, no. 3, pp. 649-655, 1996. 
[30] R. Aggarwal and S. Singh, "AHP and extent fuzzy AHP approach for prioritization of performance measurement attributes," International Journal of Social, Education, Economics and Management Engineering, vol. 7, no. 1, pp. 43-48, 2013.

[31] Y. O. Ouma, C. Yabann, M. Kirichu, and R. Tateishi, "Optimization of urban highway bypass horizontal alignment: a methodological overview of intelligent spatial MCDA approach using fuzzy AHP and GIS," Advances in Civil Engineering, vol. 2014, Article ID 182568, 26 pages, 2014.

[32] A. Kaufmann and M. M. Gupta, Introduction to Fuzzy Arithmetic Theory and Applications, Van Nostrand Reinhold, New York, NY, USA, 1991.

[33] M. B. Javanbarg, C. Scawthorn, J. Kiyono, and B. Shahbodaghkhan, "Fuzzy AHP-based multicriteria decision making systems using particle swarm optimization," Expert Systems with Applications, vol. 39, no. 1, pp. 960-966, 2012.

[34] J. J. Buckley, "Fuzzy hierarchical analysis," Fuzzy Sets and Systems, vol. 17, no. 3, pp. 233-247, 1985.

[35] T.-Y. Hsieh, S.-T. Lu, and G.-H. Tzeng, "Fuzzy MCDM approach for planning and design tenders selection in public office buildings," International Journal of Project Management, vol. 22, no. 7, pp. 573-584, 2004.

[36] G. R. Jahanshahloo, F. H. Lotfi, and M. Izadikhah, "An algorithmic method to extend TOPSIS for decision-making problems with interval data," Applied Mathematics and Computation, vol. 175, no. 2, pp. 1375-1384, 2006.

[37] T.-C. Wang and T.-H. Chang, "Application of TOPSIS in evaluating initial training aircraft under a fuzzy environment," Expert Systems with Applications, vol. 33, no. 4, pp. 870-880, 2007.

[38] I. Ertugrul and N. Karakasoglu, "Performance evaluation of Turkish cement firms with fuzzy analytic hierarchy process and TOPSIS methods," Expert Systems with Applications, vol. 36, no. 1, pp. 702-715, 2009.

[39] M. Ashrafzadeh, F. R. Mokhatab, and N. I. Mollaverdi, "Application of fuzzy TOPSIS method for selection of warehouse location: a case study," Interdisciplinary Journal of Contemporary Research Business, vol. 3, no. 9, pp. 655-671, 2012.

[40] C.-C. Sun, "A performance evaluation model by integrating fuzzy AHP and fuzzy TOPSIS methods," Expert Systems with Applications, vol. 37, no. 12, pp. 7745-7754, 2010.

[41] C.-T. Chen, C.-T. Lin, and S.-F. Huang, "A fuzzy approach for supplier evaluation and selection in supply chain management," International Journal of Production Economics, vol. 102, no. 2, pp. 289-301, 2006.

[42] M. Johanns and J. Craig, Pavement Maintenance Manual, NDOR, Grand Island, Neb, USA, 2002. 

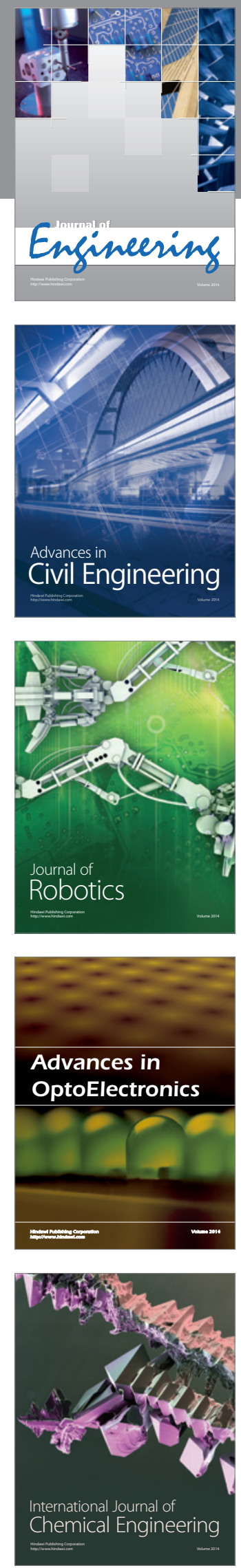

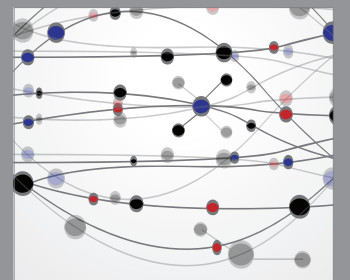

The Scientific World Journal
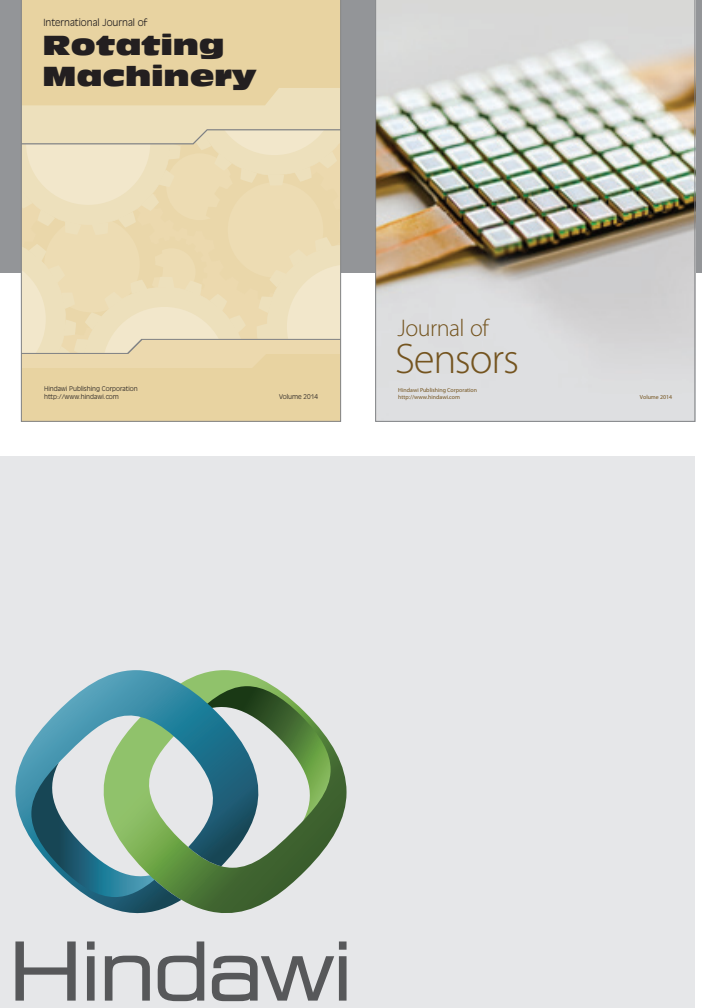

Submit your manuscripts at http://www.hindawi.com
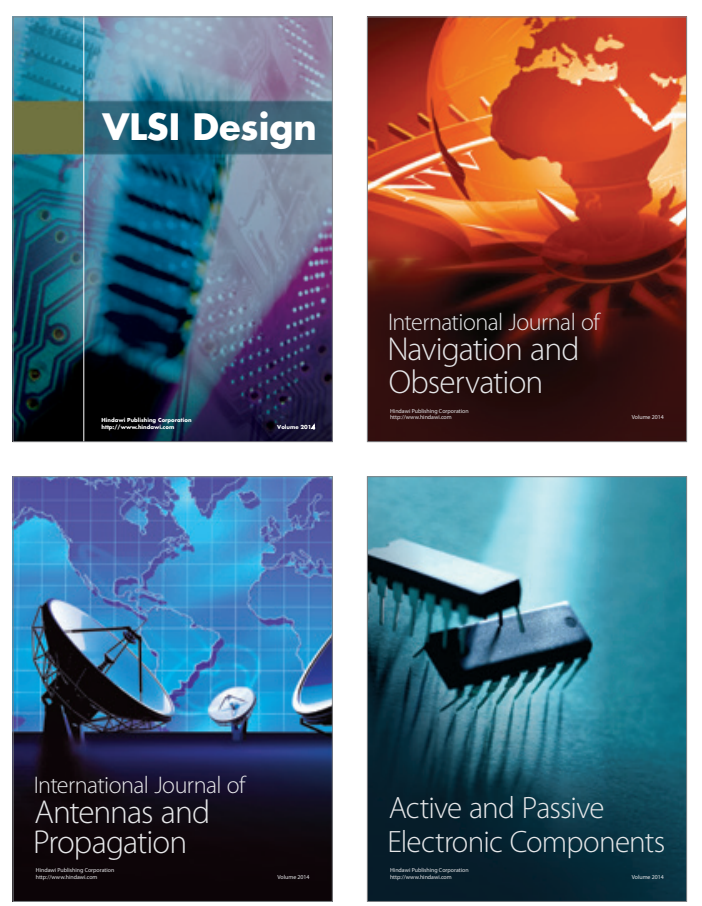
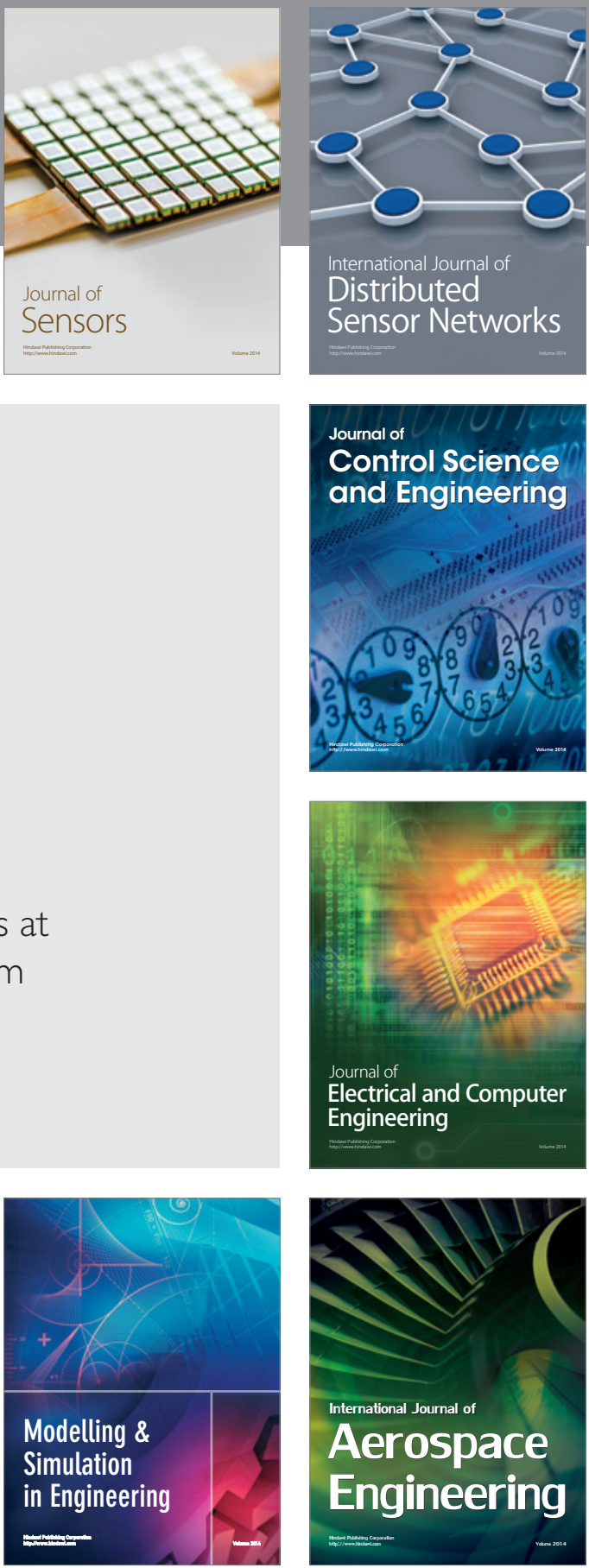

Journal of

Control Science

and Engineering
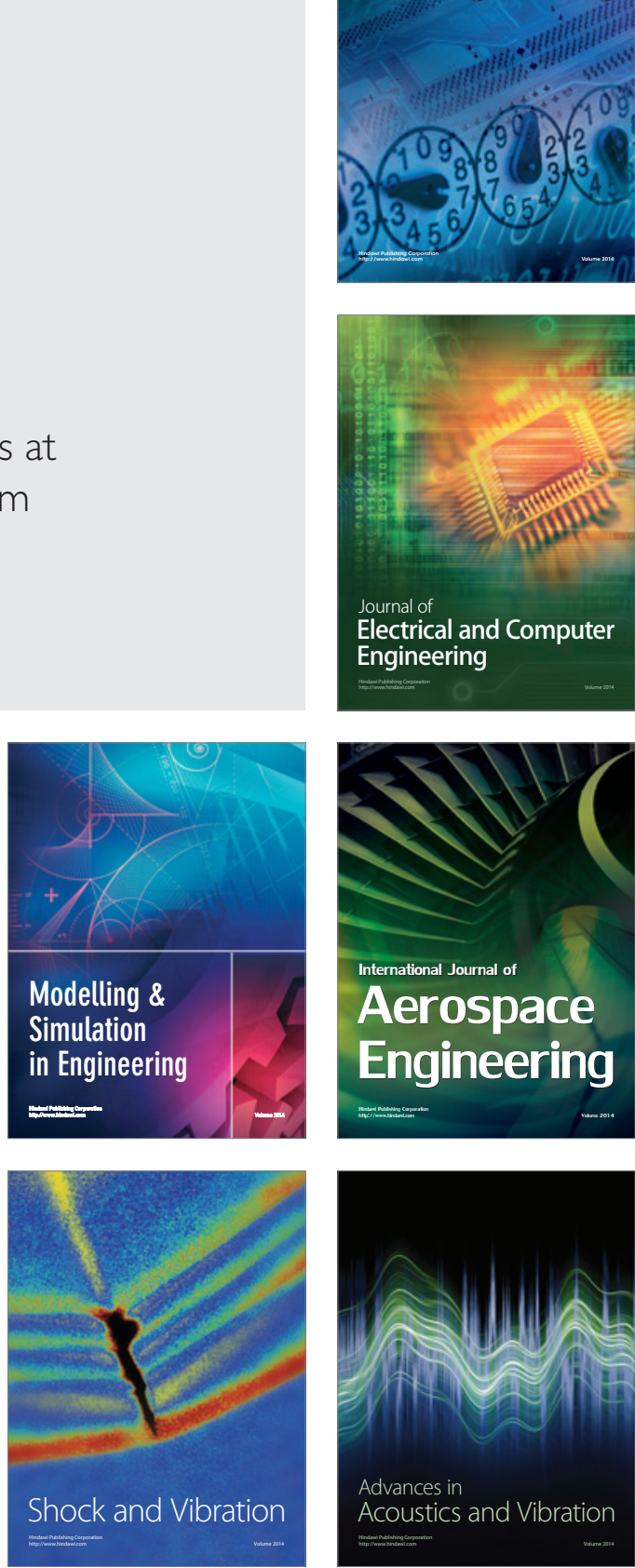